U N I K A S S E L

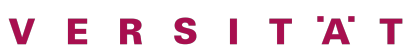

\title{
Assessing the Monetary Value of Vehicle-to-Grid considering Battery Degradation: Agent-Based Approach
}

\author{
By \\ Pradyumansinh Raj \\ A Thesis submitted to \\ the Faculty of Engineering at \\ Cairo University and Kassel University \\ In Partial Fulfillment of the \\ Requirements for the Degree of \\ Master of Science \\ in \\ Renewable Energy and Energy Efficiency \\ for the Middle East and North Africa Region \\ (REMENA)
}

University of Kassel - Kassel, Germany

Faculty of Engineering, University of Cairo - Giza, Egypt

June 2019 


\title{
Assessing the Monetary Value of Vehicle-to-Grid considering Battery \\ Degradation: Agent-Based Approach
}

\author{
By \\ Pradyumansinh Raj \\ A Thesis submitted to \\ the Faculty of Engineering at \\ Cairo University and Kassel University \\ In Partial Fulfillment of the \\ Requirements for the Degree of \\ Master of Science \\ in \\ Renwable Energy and Energy Efficiency \\ for the Middle East and North Africa Region
}

(REMENA)

Under the Supervision of

Prof. Dr. -sc.techn. Dirk Dahlhaus

University of Kassel, Germany

Prof. Dr. Adel Khalil

Cairo University, Egypt

Auke Hoekstra

Eindhoven University of Technology, Netherlands

$$
\begin{gathered}
\text { Dr.-Ing Nour Mansour } \\
\text { University of Kassel, Germany }
\end{gathered}
$$

University of Kassel - Kassel, Germany

Faculty of Engineering, University of Cairo - Giza, Egypt 
"Truth emerges more readily from error than from confusion." - FRANCIS BACON 


\section{Declaration of Authorship}

To the best of my knowledge, I do hereby declare that this thesis is my own work. It has not been submitted in any form for another degree or diploma to any other university or other institution of education. Information derived from the published or unpublished work of others has been acknowledged in the text and a list of references is given.

Date: June 2019

Signed:

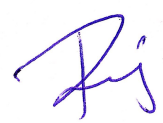




\section{Abstract}

Electrification of the transport sector is increasing the electricity demand in the energy system. On the other hand, penetration of renewable energy sources are increasing the intermittency in the power system, posing the challenge in the realtime balancing of the electricity supply and demand. With V2G or bi-directional charging, it is possible to link both the system in a way that can provide synergistic benefits to both. In V2G research, system benefits have been studied thoroughly in the past compared to EV user benefits of V2G services. Moreover, research on EV user benefits lacks the socio-technical approach that takes into account user behaviour, social values, and business models.

Considering above mentioned research gaps, in this thesis V2G monetary benefits are researched for the EV users in the Netherlands. The study specifically focuses on EV users trading at spot market in the Netherlands while providing V2G storage (arbitrage). Moreover, simplistic battery degradation cost and lifetime economic analysis have also taken into consideration for the calculation of V2G net benefits. This research has been conducted under SparkCity agent-based model framework, which has been developed at the the Eindhoven University of Technology and currently maintained by Zenmo simulations in the Netherlands.

Agent-based modelling approach comprises the heterogeneous behaviours and characteristics of the agents (EV users), their collective influence on the spot market and individual agent's V2G benefits which is affected by the global change in prices of the spot market. $\mathrm{V} 2 \mathrm{G}$ charging strategy has been compared with baseline charging strategy and cost-based charging strategy for the comparison of the benefits. EV users with diverse characteristics in the neighbourhood have been compared to study the effects of individual characteristics on monetary benefits. Simulation has been run for three different years with varying EV adoption rate and renewable energy penetration into the energy system.

Results show $\mathrm{V} 2 \mathrm{G}$ as a promising solution for the energy system with high renewable and EVs. It can provide a tremendous amount of flexibility and storage to the system and offset the storage costs into the future energy system. However, V2G benefits for EV users under spot market are lower comparing to other market mechanisms. It might be less attractive for users to provide storage for a more extended period with comparably less profit gain. Moreover, battery degradation costs are higher taking into consideration current battery prices. However, with more PV installation in the renewable mix, the potential to gain benefits during the day time increase significantly. 


\section{Acknowledgements}

I would like to express my deepest gratitude to team of ZEnMo in the Netherlands for not just hosting me for the valuable thesis topic but also providing constant help and support during my stay in the Netherlands. I am grateful to Auke Hoekstra for his constant supervision, fruitful conversations and his valuable time. I want to thank Michiel for all the discussions, feedback and insights which he has provided to me during my thesis. I also want to thank Peter for all the arrangements he has done and opportunity he has provided to me.

I would like to thank Prof. Dr.-sc.techn. Dirk Dahlhaus and Prof. Dr. Adel Khalil for supervising my thesis and providing the needed guidance during my thesis project. I also express my gratitude to Dr.-Ing. Nour Mansour for her valuable support and guidance throughout the period of my thesis.

I want to thank Ms. Anke Aref for providing me valuable support and help during the master program in Germany. I would also like to thank and appreciate all the efforts that Dr. Sayed Kaseb has put into during REMENA program in Egypt.

I am most grateful to my parents Harisinh Raj \& Varsha Raj for their love, motivation and support during all of my student years. 


\section{Contents}

Declaration of Authorship i

$\begin{array}{lll}\text { Abstract } & \text { ii }\end{array}$

Acknowledgements

List of Figures vii

List of Tables $\quad$ viii

1 Introduction 1

1.1 Background . . . . . . . . . . . . . . . . . . . 1

1.2 Literature Review . . . . . . . . . . . . . . . . . . . 2

1.3 Research Question . . . . . . . . . . . . . . . . . . 4

1.4 Research Framework . . . . . . . . . . . . . . . . . . . . 4

1.5 Scientific and Societal Relevance . . . . . . . . . . . . . 5

1.6 Thesis Outline . . . . . . . . . . . . . . . . 5

$\begin{array}{lll}2 & \text { Theoretical background } & 7\end{array}$

2.1 Agent-Based Modelling . . . . . . . . . . . . . . . 7

2.2 Battery Degradation of Electric Vehicles . . . . . . . . . . . 9

3 Methodology 12

3.1 System Description . . . . . . . . . . . . . . . . . . . . 12

Overview of Characteristics in the Simulated Neighbourhood 13

Bottom-up Modelling Approach . . . . . . . . . . . . . 13

Structure of the Agents . . . . . . . . . . . . . . 14

Software Implementation . . . . . . . . . . . . . . 14

3.2 Household Load . . . . . . . . . . . . . . . . . . . . . . . . . . . 15

3.3 Driving Behaviour . . . . . . . . . . . . . . . . . . . 16

3.4 Charging Behaviour . . . . . . . . . . . . . . . 17

3.5 Charging Strategies . . . . . . . . . . . . . . . . . . 17

3.5.1 Vehicle-to-Grid Strategy (V2GS) . . . . . . . . . . 18

Implementation of Backward Induction Algorithm . . . . . 19

Time-steps . . . . . . . . . . . . . . 20

3.5.2 Cost Based Charging Strategy (CBCS) . . . . . . . . . . 20

3.5.3 Uncontrolled Charging Strategy (UCS) . . . . . . . . . . . . 22

3.6 Spot Market . . . . . . . . . . . . . . . . . . . . . . . . . 22

Input Data and Assumptions . . . . . . . . . . . . . 23

3.6.1 Demand Shift on Spot Market Due to EV Charging . . . . 23

3.7 Electricity Prices for EV Charging . . . . . . . . . . . . . . . 24

Taxation on V2G . . . . . . . . . . . . . 25

3.8 Battery Degradation Costs and Lifetime Economic Analysis . . . . 26 
4 Results $\quad 30$

4.1 Influence on National Energy System . . . . . . . . . . . . . . . . . 30

4.1.1 Demand Shift on the National Level Due to Different Charging Strategies . . . . . . . . . . . . . . . . 31

4.1.2 Influence on Average Spot Market Prices Due to Different Charging Strategies . . . . . . . . . . . . . . . 32

4.1.3 Influence on Local Electricity Network Due to Different Charging Strategies . . . . . . . . . . . . . . 34

4.2 Monetary Benefits . . . . . . . . . . . . . . . . . . . 34

4.2.1 Selected EV users for the Comparison of Monetary Benefits 34

4.2.2 Weekly SOC Distribution of EV Users under UCS, CBCS, and V2GS . . . . . . . . . . . . . . . . . . . . . 35

4.2.3 Battery energy throughput under UCS, CBCS and V2GS . 37

4.2.4 Charging Costs and V2G Benefit . . . . . . . . . . . . 38

4.2.5 Battery Degradation Cost and V2G Net Benefit . . . . . . . 40

4.3 Sensitivity Analysis . . . . . . . . . . . . . . . . 43

EV charging power sensitivity analysis . . . . . . . . . 43

5 Conclusion $\quad \mathbf{4 5}$

5.1 Influence of V2GS on Energy System . . . . . . . . . . . . . . . . 45

5.2 Monetary Benefits of EV Users . . . . . . . . . . . . . . . . . 46

5.3 Battery Degradation Costs and Lifetime Economic Analysis . . . . 46

6 Discussion $\quad 48$

6.1 Limitations .. . . . . . . . . . . . . . . . . . . 48

6.2 Future Work ...................... 49

$\begin{array}{lr}\text { Bibliography } & 50\end{array}$

A OViN Data Distributions $\quad 55$

B Local Electricity Network Load $\quad 57$

C Spot Market Prices Validation $\quad 58$ 


\section{List of Figures}

1.1 Storage technologies for Europe, 2000-2100 . . . . . . . . . . 2

1.2 V2G module integration into SparkCity model . . . . . . . . 5

2.1 Structure of an agent-based model . . . . . . . . . . . . . . 8

3.1 General structure of the model with key agents in the context of agent-based modelling . . . . . . . . . . . . . . 12

3.2 Attributes of the building agent . . . . . . . . . . . . . 14

3.3 Attributes of the adult agent . . . . . . . . . . . . . . 14

3.4 Attributes of the EV agent . . . . . . . . . . . . . 15

3.5 Different household load-profiles in the neighbourhood. (A) Detached house, (B) Cornered house (C) Terraced house (D) Apartment . . 16

3.6 Number of adult agents making work-trips, evening/leisure trips and day trips in different point of time during two days . . . . . . . . .

3.7 Example of different charging strategies implementation, CBCS and $\mathrm{V} 2 \mathrm{G}$ are the optimised charging strategies while UCS is uncontrolled charging. . . . . . . . . . . . . . . .

3.8 Merit-order with supply curve, demand curve and their intersection

3.9 The APX day-ahead prices and fitted supply curves representing different generators and their capacity in $2016 \ldots$. . . . . . .

3.10 Composition of electricity prices for the EV charging as from the source [12] and discussion with expert in the Netherlands . . . . .

4.1 Hourly average demand shift due to the charging of EVs on national compared with an average demand of the Netherlands . . . . . . .

4.2 Average market prices for UCS, CBCS , V2GS and the prices without the demand shift due to charging . . . . . . . . . . . .

4.3 Weekly SOC distribution of different EVs (related to users) under different charging strategies . . . . . . . . . . . . . .

4.4 Total battery energy throughput, charged $\mathrm{kWh}$ and discharged $\mathrm{kWh}$ of EVs under UCS (baseline scenario), CBCS and V2GS . . . . . .

4.5 Comparison of energy costs based on different charging strategies (UCS,CBCS,V2GS) and V2GS benefit compared to UCS and CBCS

4.6 Comparison of charging costs based on different charging strategies (UCS,CBCS,V2GS) and V2GS benefit compared to UCS and CBCS 40

4.7 Projected Battery prices and Battery cycles (100\%DoD) . . . . . . 41

4.8 V2G net benefit and degradation costs . . . . . . . . . . . 42

4.9 V2G net benefit and degradation costs: 2019-2030 . . . . . . . 43

4.10 V2G benefit w.r.t. UCS with varying charging power . . . . . . . 44

$4.11 \mathrm{~V} 2 \mathrm{G}$ benefit w.r.t. $\mathrm{CBCS}$ with varying charging power . . . . . . 44

A.1 Distributions of departures work trips by car . . . . . . . . . 55

A.2 Distributions of departures non-work trips by car . . . . . . . 55 
A.3 Numbers of departure per travel motive . . . . . . . . . . . 55

A.4 Work trips of adults using car . . . . . . . . . . . 55

A.5 Motive of trip after work trip . . . . . . . . . . 56

A.6 Distribution travel distance car work trips workday . . . . . . . . 56

A.7 Travel time car vs travel distance . . . . . . . . . . . . . 56

B.1 Local electricity load due to different charging strategies in 2019,2025

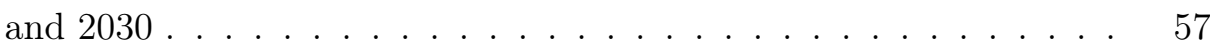

C.1 Comparison of EPEX and Model generated average spot market price for $2016 \ldots \ldots \ldots \ldots \ldots$ 


\section{List of Tables}

3.1 Overview of characteristics in the simulated neighbourhood . . . 13

4.1 Specification of the EV users selected from the neighbourhood for the comparison of V2G monetary benefits . . . . . . . . . 35

C.1 RMSE values $(€ / M W h)$ due to different charging strategies in 2019, $2025,2030 \ldots \ldots \ldots \ldots \ldots \ldots \ldots$ 


\title{
List of Abbreviations
}

\author{
ABM Agent Based Modelling \\ GIS Geographic Iformation System \\ DoD Depth of Discharge \\ SOC State Of Charge \\ SoH State of Health \\ BTMS Battery Thermal Management System \\ DES Discete Event Simulation \\ SD System Dynamics \\ NCA Lithium Nickle Cobalt Aluminimum Oxide \\ NREL National Renewable Energy Laboratory \\ NCM Lithium Nickle Cobalt Manganese Oxide \\ UCS Uncontrolled Charging Strategy \\ CBCS Cost Based Charging Strategy \\ V2GS Vehicle to Grid Strategy \\ RMSE Root Mean Square Error \\ PCM Phase Change Material \\ DAG Directed Acyclic Graph \\ SRMC Short Run Marginal Cost \\ EFC Equivalent Full Cycle
}




\section{Chapter 1}

\section{Introduction}

\subsection{Background}

Special Report on Global Warming prepared by IPCC in 2018 clearly states the need for rapid, far-reaching and emergent actions towards limiting global warming to 1.5 ${ }^{\circ} \mathrm{C}$ [51]. This means a decline in global emission of $\mathrm{CO}_{2}$ by $45 \%$ from 2010 levels by 2030 , and reach net zero by 2050 . It can only be achieved with rapid decarbonization of the global economy with more renewable energy deployment and electrification of the transport sector [15].However, growing shares of renewable energy sources (RES) into electric power system increases variability and uncertainty of the power production which poses new challenges in keeping the real-time balance between electricity supply and demand [60]. This increases the immense need for system flexibility and storage.

Electrification of the transport sector is speeding up with electric vehicles uptake in the past few years. It is primarily because of the decreasing cost of battery packs, policy incentives, and tight regulation [54]. In the coming decade, it is expected that the cost of battery packs will fall faster than previous rate which will result in tremendous growth in the share of electric vehicles [3]. An introduction of growing EV (electric vehicle) fleet will require technical as well as regulatory reforms at different levels in the energy system. However, if these issues are adequately addressed, various advantages can be gained with EV penetration.

As vehicles are being expected to park for more than $92 \%$ time [17], in the case of EV fleet scenario, vehicles can provide their batteries to the electricity grid for ancillary services as well as can be viewed as energy storage for the energy system with pooling of the vehicles [23]. Several terms have arisen in describing the link of the electricity system and transportation, such as vehicle-grid integration (VGI), grid-integrated vehicles (GIV), bi-directional charging or most commonly used vehicle-to-grid (V2G). From now on, in this report abbreviation of the vehicle-to-grid (V2G) will be used for being relevant to the stream of literature [48].

With the increasing rate of electrification of the vehicles, potential of V2G is also increasing in providing the need of system flexibility and storage. It can be observed in the figure 1.1, which is representing the role of different energy storage technologies for the integration of high shares of RES in the long-term evolution of the European power system. 

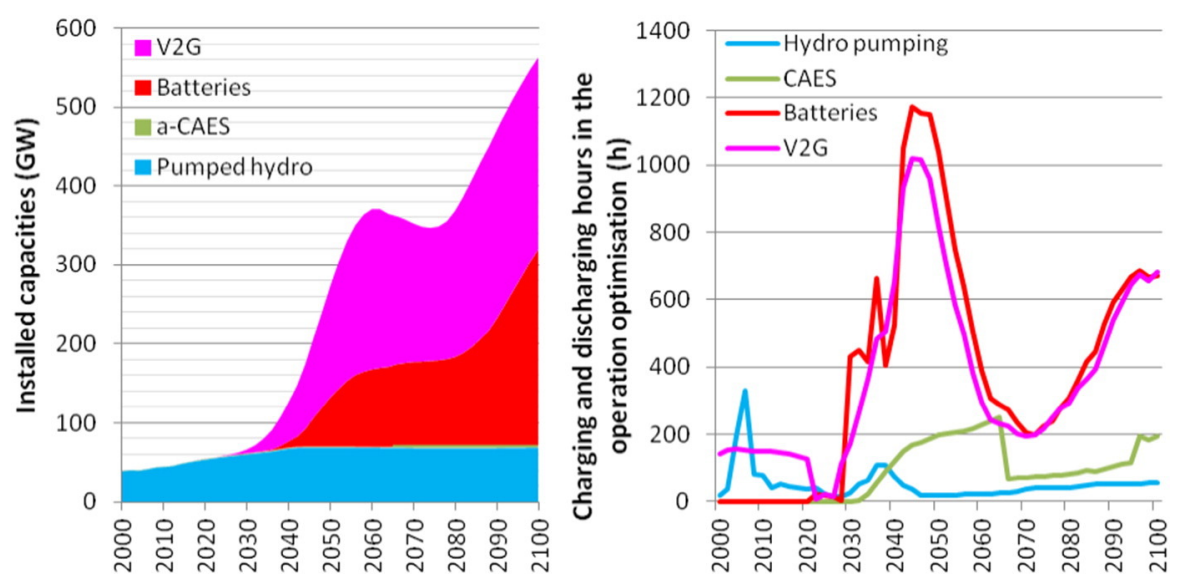

FiguRE 1.1: Capacities (left) and hours of utilization (right) in the operation of different optimized energy storage technologies for Europe, 2000 -2100. Reprinted from [14].

\subsection{Literature Review}

Concept of V2G was first explored by [23]. In the paper, authors have explored the possibilities of utilising the electric vehicles for the benefits of the electric power system with increasing intermittent RES. First V2G demonstration project was realised by [10], when the cost of vehicle is higher, battery capacity is adequate for transport use and battery life is limited, it is only suitable for the high value market such as frequency regulation and imbalance, which is also known as ancillary services. These markets require quick-response and shorter operating duration for dispatching, which requires shallow cycling of EV battery compare to other power market. Moreover they provide the payments for both capacity and energy provided. However, [24, 25] observed that these markets are very small in size and will be saturated with very low penetration $(3 \%)$ of EV fleet providing storage to these markets. The same authors have concluded that with the approach to the saturation of the ancillary services market, electric vehicles will be more suitable to be utilised as storage unit to facilitate integration of RES.

After the realisation of the V2G concept and key findings from the initial projects, it is realised that an individual EV connected to grid as a distributed energy source (DER) has very less impact on the grid. Their batteries needs to be grouped or aggregated in order to make effective impact at grid level [5]. Moreover to be compliant and to trade with electricity market, larger capacity of storage/generation is needed. In [5], author has proposed a conceptual framework for the practical implementation of $\mathrm{V} 2 \mathrm{G}$ with focus on aggregation of EVs. [7] further explore the role of EV aggregator in the electricity market with describing the operational, informational and decision-making phase in day-ahead, intra-day and reserve market. Furthermore, it also sets the base for the future modification into the rules and regulation of electricity market to accommodate EVs.

Several studies have been focused in the past on optimising charging/discharging of the electric vehicles from the point of view of electricity markets. It means charging the electric vehicles when higher amount of free power capacities or RES are producing energy with very low prices, and discharging it in the time of higher market prices or low amount of RES capacities are generating the energy. Taking 
it into consideration Optimized bidding strategies from the aggregator's perspective has been researched thoroughly by many articles. Their main focus has been on spot-market (day-ahead \& intra-day) and reserve market with uncertainty in the prices and stochastic energy demand from the EV users $[22,6,8]$.

As focus of this thesis is already decided, further literature research is narrowed down to Dutch electricity market. The authors have explored the bi-directional trading of electric vehicles at Dutch electricity market [21, 61]. They both have focused on Regulating and Reserve Power (RRP) market in the Netherlands, as it is the most feasible operational market for the provision of V2G services. [61] has pointed out the limitations of the RRP market, which are symmetric capacity bidding or regulation up and down and minimum bidding size (4 MW) set by TenneT, the TSO (RRP market organiser and controller). He further concluded that with intra-day market (IDM) theses limitations can be overcome. Moreover, IDM will be important in the future as it allows to fully utilise the short-term, low-duration trading capabilities of V2G.

From the EV user perspective, intelligent trading on the day-ahead market can significantly reduce the cost of charging in both uni-directional and bi-directional charging/discharging. However, at the same time it is cumbersome to predict the correct EV energy demand for the day before they get charged.To cope with such problem, aggregator can obtain two-stage approach in which they trade on day-ahead market by forecasting EV energy demand, and on the day of delivery they can handle the deviations from the original forecast at IDM. It is possible to trade before 5-minutes of delivery on IDM in the Netherlands. Such approach is practical and legal, moreover, several studies have also explored it for different countries in Europe [37, 45]. Based on this approach further modelling assumptions and simplifications will be made in this research.

Studies in the past have mostly focused on system benefits of V2G services, and very narrowly researched different EV users. Most of these studies doesn't take into account the user driving pattern and varying characteristics of the users, which are very important factors in determining the benefits of $\mathrm{V} 2 \mathrm{G}$ services provision for an EV users. Moreover, it is also important for an aggregator or service provider to look into individual EV user driving and charging behaviour, to make adequate compensation for their battery provision to $\mathrm{V} 2 \mathrm{G}$ services. This research will specifically focus on individual EV user behaviour and characteristics in the context of V2G monetary benefit.

Research into V2G literature gives a very little insight into user aspects of V2G. Most of the articles or researches assumed users as a optimising agent into the system, which behaves for the system profit maximisation or their own financial benefits. Researchers in their summary of socio-technical review of V2G, have mentioned about the common linkage of technical and financial assessment of V2G. Further, they have noted that most of $\mathrm{V} 2 \mathrm{G}$ studies lack interdisciplinary approach in the modelling and take exogenous assumptions about the users in terms of EV adoption, driving behaviour,etc [47, 48]. 


\subsection{Research Question}

During the literature research of $\mathrm{V} 2 \mathrm{G}$, several research gaps have been identified. Over the years, V2G research have been focused on techno-economical aspects of V2G. In the systematic review from [47], researcher has mentioned the need for socio-technical approach in V2G research, which not just include technical and financial aspects, but also extends analysis to social values, business models and user behaviour. Same gaps have also been realised in the V2G research in the Netherlands. Taking these gaps into consideration, a research question has been formulated.

What is the monetary value created for different EV users who provide energy storage (V2G arbitrage) under spot market in the Netherlands? Sub-questions:

- What are the most important factors affecting V2G monetary value?

- How do these factors influence the V2G monetary value?

The aim of this research question is to provide an insight into V2G services profitability from different EV users perspective in the Netherlands. It also takes into account the endogenous and exogenous factors affecting the V2G benefits. This factors will be discussed further in details.

On the later stage of the study, research question has been extended to investigate the influence of different charging strategies (UCS, CBCS, V2GS) on national energy system (spot market demand, spot market prices). It is possible to integrate above mentioned question into the existing research question because of the capabilities of the modelling approach taken into account.

\subsection{Research Framework}

To investigate the formulated research question, it is needed that modelling approach include heterogeneous user behaviour, their influence on each other as well as profit maximisation algorithm to trade on spot-market. Such complex sociotechnical interactions are only possible to model with an agent-based modelling approach (ABM). Based on such complex socio-technical interactions, multi-level perspective and transition-management theory, agent-based SparkCity model has been developed at Eindhoven University of Technology in the Netherlands to answer the questions regarding future Dutch EV environment [19].

Aim of the SparkCity model, is to model and simulate the dynamics of EV sector in order to understand the impact of its on different actors and lay out suitable strategies for them. These actors could be policy makers, charge point operators, distribution system operators and electric vehicles users. In SparkCity model, actors/agents are modelled with realistic behaviour and spatio-temporal simulations as observed by domain-experts and empirical data-sets. Moreover, it can also able to load GIS based roads network, buildings and parking location, charging network and electricity network for the multi-purpose analysis.

In figure 1.2, it can be observed that there are local agents living in the neighbourhood and global agents or modules are created to add specific functionalities or 
behaviour to local agents. After adding these modules EV adoption rate, need for charging infrastructure and impact of smart charging in the neighbourhood can be studied respectively. In the same manner, V2G module can be added to SparkCity model in order to study the formulated research question.

From the elaboration of the SparkCity model, it can be observed that it provides vast possibilities to analyse the future scenarios concerning the EV charging infrastructure. Moreover, It suits perfectly well with our research question at hand.

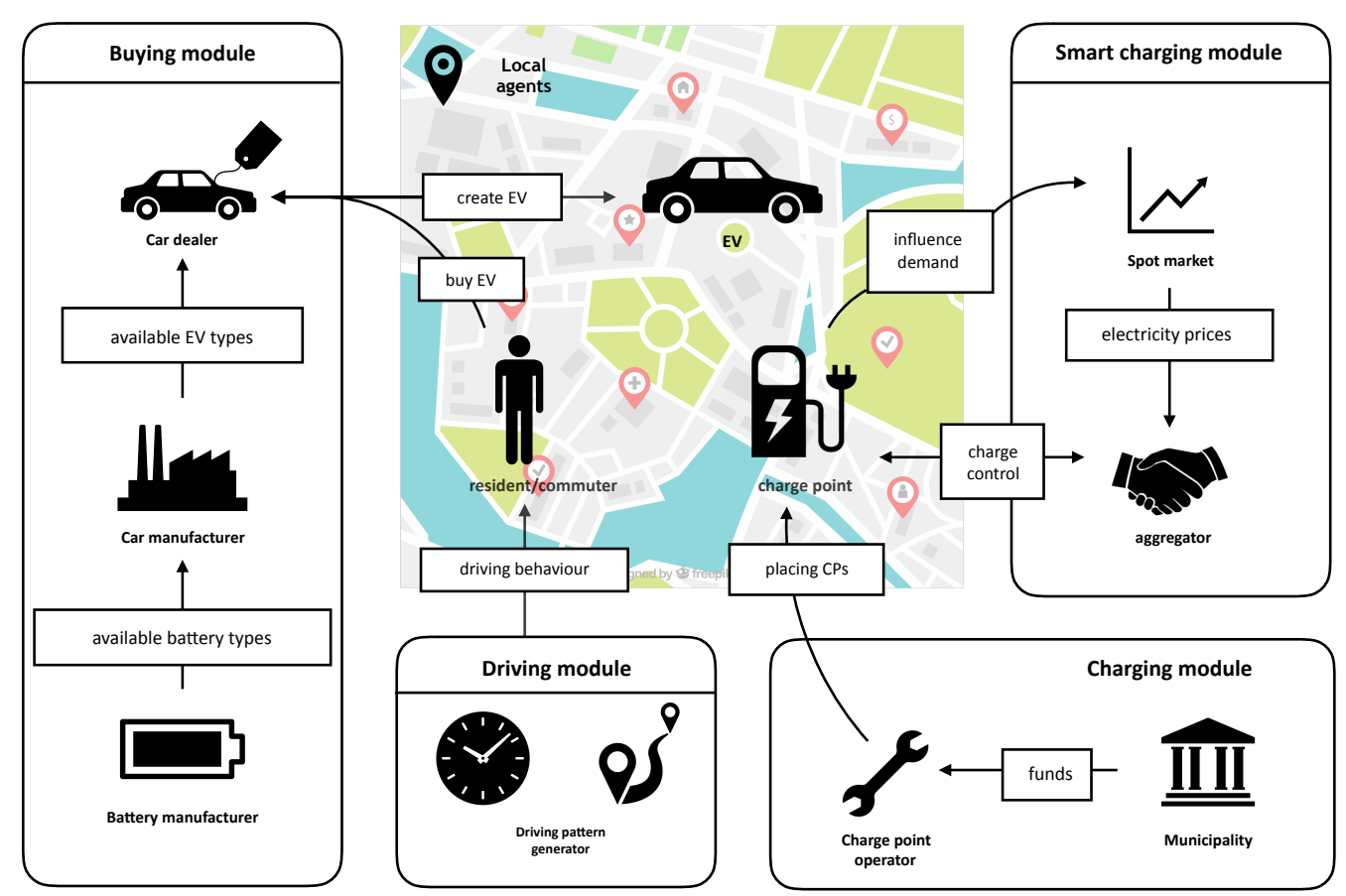

Figure 1.2: Overview of the SparkCity model

\subsection{Scientific and Societal Relevance}

As mentioned in the literature review, V2G research have been heavily focused on techno-economic optimisation and lacks the socio-technical approach, which not just include technical and economical but also social, political and environmental aspects to it. In this thesis, for the first time EV user's V2G monetary benefits has been studied considering individual behavioural and EV characteristics, exogenous and endogenous effects on global electricity prices. Moreover, it also includes collective influence of different charging strategies on global electricity prices and comparative benefits of V2G to other charging strategies.

\subsection{Thesis Outline}

This research takes on the following approach 
- Chapter 2 represent the theoretical knowledge regarding agent-based modelling approach, and includes theory and literature review regarding battery degradation of electric vehicles.

- Chapter 3 explains the undertaken methodology to research the V2G monetary benefits of the EV users. It will describes the modelled neighbourhood, created agents, their attributes and behaviour. It will also include the explanation for the spot market component in the model and battery degradation cost and economic analysis.

- Chapter 4 will presents the results regarding the influence of different charging strategies on national energy system, which will include influence on spot market demand, spot market prices and local electricity network. In the second section it present the results regarding the monetary benefits, their characteristics, weekly SOC distribution and battery degradation costs.

- Chapter 5 will conclude the results separately for energy system influence, monetary benefits and battery degradation costs

- Chapter 6 will present discussion on study which includes limitations of the study and recommended future work. 


\section{Chapter 2}

\section{Theoretical background}

In this chapter, agent-based modelling approach will be explained in detail from the fundamental concepts of it. Section 2 will focus on basics of battery degradation and current state of research into V2G related battery degradation.

\subsection{Agent-Based Modelling}

Current energy systems are evolving into the decentralised systems, where involvement of an individual social actors are increasing. This makes energy system transition from technical system to more complex socio-technical system. Such system features various complex interactions between different entities and collective influence of its on the system as a whole. That makes system, difficult to analyse the effect of certain strategies without modelling it in a comprehensive and detailed manner.

Agent-based modelling approach are perfectly suitable to study above mentioned complex systems and it's evolution. It is bottom-up modelling technique previously used in non-computing related scientific domains such as biology, ecology and social science [38]. In Agent-based modelling, complex system are comprised of autonomous and interacting agents. Each agent can be modelled with set of behavioural rules, which allows them to execute the actions, interact with other agents and adapt to their behaviour. From the simultaneous interactions of the diverse type of agents collective behaviour of the system emerges, which is also known as emergence [31].

Figure 2.1 represent the basic structure of an agent-based model. As author puts in [31], structure of an agent based model can be explained by three key elements [adapted from [31]].

1. A set of agents, their attributes and behaviour

2. A set of agents relationships and their interaction methods

3. The Agent's environment

Starting from first element, it describes the definition of the the agent and what it comprised of at fundamental level. The agent can be simply expressed by it's state and rules based on which it changes the state. The state is the simple collection of parameters or attributes that defines the agent at the moment in time. While rules are the internal models or transformation functions that help translate the agent's state into the actions or the different states. Rules can be defined by simple decision 


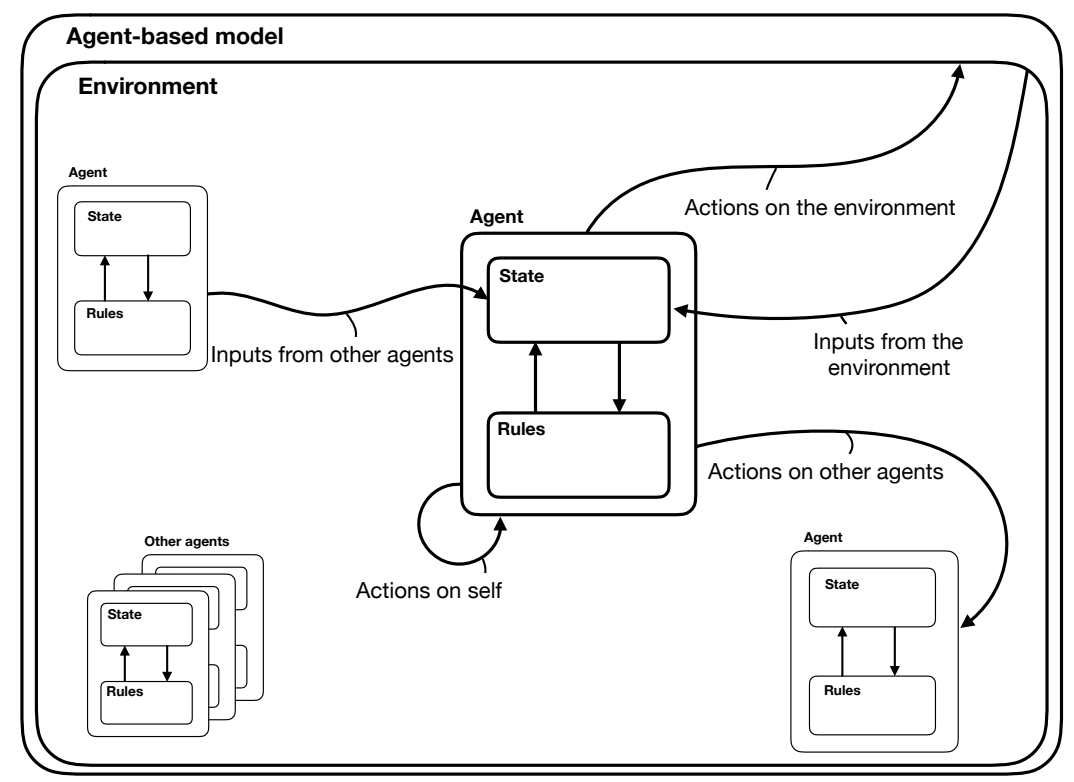

FiguRE 2.1: Structure of an agent-based model. Adapted from [58]

making algorithm, optimisation algorithm or very complex adaptive algorithms such as AI.

Agents are the software entities in the context of computer programming. In terms of object oriented programming, agent's state can be defined by static or dynamic variables in the class. Agent's decision rules can be programmed by the methods. Class of an agent can also have multiple instances which represent the different agents and it differs from one agent to another based on variation in relevant data or programmed rules [52].

In $\mathrm{ABM}$, agents are interacting with other agents and also with environment to access the specific information or inputs as it can be visualised in the figure 2.1. It is equally important to model how agents are connected to each other and what kind of information they are transferring. It is termed as model's topology or interconnectedness [30], which includes network of agents and links between them. It is easier to model topology of technical agents by defining its technical components and social actors associated to it. However, social networks are difficult to define as because of lack of data and constantly changing the links between the actors.

Agent's environment is the space where agent moves around or/and lives. It provides the necessary spatial information about the agent or to the agent. This information can be other connected agent's locations or movement of the agents in the model. There are several topologies which are used as physical environment for different problems at hand.

ABM has many other advantages over other modelling approaches. It provides flexibility of incorporating several other modelling approach such as Discrete Event Simulation (DES), System Dynamics (SD), Analytical Modelling or Mathematical Optimisation in the agent or in the parallel simulation. With such flexibility, different components of ABM can be modelled in comprehensive manner [9]. For instance, model like SparkCity where several users charge their electric vehicles 
with different charging strategies which involves certain constraints can be modelled with mathematical programming in to an agent.

Validity of the modelling is important to ensure that the model is correctly representing the system. However, it remains a big challenge in ABM. It is because of ABM's non-linearities, size of model, numbers of parameters and level of detail. However, author in [26] mentioned the two methods of ABM validation which includes the method of plausibility checks of input output of overall system by domain experts or stakeholder. Second method includes internal structure and behavioural validity by empirical validation.

\subsection{Battery Degradation of Electric Vehicles}

With an ideation of in-depth analysis of battery degradation cost, literature research on battery degradation have done thoroughly. Main internal mechanism of battery degradation have been studied at electro-chemical level in order to grasp complete knowledge of degradation. Although, in this study battery degradation costs have not been calculated with such details due to time and algorithm constraints, brief explanation of these mechanism and their influence on battery degradation will help reader understand the fundamentals of battery degradation.

As this study concern with EV batteries, and most common battery type in current EVs are lithium-ion batteries, further study and review has been done on lithium-ion batteries. It is also important to note that degradation also depends on different types of battery chemistries. However, in this study generalised review of battery degradation has been made.

Li-ion batteries are comprised of positive and negative electrodes, electrolyte and separator. Positive electrodes (cathode) are made of metal oxides and negative electrodes (anodes) are made of carbon porous material (graphite). Electrolytes are used in batteries as a conductor of the charge in between the electrodes. During the discharge li-ions moves from anode to cathode, and during the charge this direction is reversed. It is widely accepted and known from the research that formation of solid-electrolyte interphase (SEI) in the battery is the main reason of degradation in battery chemistry [11, 27].

It has been found in the research that the layer of SEI at graphite/electrolyte inter-phase is starting to form as a protecting layer with the first cycling process of the battery. It prevents the graphite structure (anode) from decomposition [55]. However, over the time even with at the moderate conditions thickness of the layer start to increase as some of the li-ions starts to react with degradation products of the electrolyte. In this process cyclable li-ions are loss and battery capacity is degraded. Electrode degradation is starting to occur at more severe condition, which eventually leads to irreversible capacity loss. However, it is difficult to analyse the degree of effect of individual mechanism on battery capacity loss, as degradation involves combinatory influence and interactions of these mechanism [27].

As EV battery are found to be in two different states which are storage and cycling, it is important to understand how different mechanisms are influencing the degradation of the battery. It is found that cycling of the battery has significant influence on the battery degradation in compare to storage/calendar state. Degradation due to cycling increase linearly in time, and it increase logarithmically in time remained 
in storage condition [27]. It is also known as cyling ageing and calendar ageing respectively.

After studying battery degradation at electro-chemical level, key external factors affecting battery degradation have been identified. These factors are operational temperature, depth of discharge (DoD), state of charge (SOC), rate of charge and discharge, battery cycles or energy throughput [43, 42, 64]. Out of these, some of the factors depend on each others or influence other factors. For instance, battery cycles or energy throughput is function of the depth of discharge, charge-rate or discharge rate increases the operational temperature of the battery,etc.

From the research above, it is found that battery degradation is very complex phenomena to study. There are several studies have been done solely focused on degradation of electric vehicles which includes the effects of driving behaviour as well as charging behaviour on battery degradation. It has been found that this type of studies includes various types of models to study degradation or life estimation of battery. Two main approaches that are used for the loss of battery capacity in this studies are performance-based models and energy throughput models (or cycle counting). Performance-based model includes equivalent circuit models, electrochemical models, analytical models and artificial neural network models [32]. Such models are defined in very detailed and comprehensive manner and can be able to estimate highly accurate analysis of battery degradation. However, it requires empirical validation from experiments of battery cells to cover the detail of range of operating conditions [32].

On the other hand, energy throughput models ${ }^{1}$ assume that under the specific standard conditions of temperature, depth of discharge and C-rate a battery can achieve an overall energy throughput until the end of life. However, such approach is limited in accuracy, but focus on the key factors that effects the required performance of the battery. Moreover, advantage of such model is that it takes into account the variation of standard conditions and relate it with the increase or decrease in energy throughput or battery degradation. It is also highly suitable for the research at hand as it take as inputs energy throughput, DoD values and charge-discharge rate, which will be generated by the current model.

Energy throughput models are widely accepted in the V2G community for the calculation of battery degradation cost. It have also been used in the development of optimised EV charging strategies considering battery degradation costs. In [20] , with similar approach optimised EV charging strategies have been developed. However, in this research different parameters of energy throughput model were tuned and degradation values have been verified by the detailed battery model developed at NREL for Li-ion NCA batteries. Hence, it extend the capabilities of energy throughput model by validating the data with experimental investigation.

Above mentioned study concluded that degradation due to $\mathrm{V} 2 \mathrm{G}$ is mainly dominated by the temperature related costs and better thermal management should make V2G feasible at even lower prices. Similar results have been found in [64], which state that if the battery thermal management system is available in EV, battery degradation due to $\mathrm{V} 2 \mathrm{G}$ would be mostly dependent on depth of discharge (DoD) and battery cycles rather than ambient temperature.

\footnotetext{
${ }^{1}$ energy throughput models are also known as Ah-throughput models which takes into consideration Ah throughput
} 
Real world analysis of the EV's performance and capacity loss has also been studied. However, it doesn't provide concrete relations between the effecting factors and degradation. But it can surely fill the gaps while making assumptions of the degradation calculation. Study of battery degradation data of Tesla Model S has been done by the researcher for the Netherlands and Belgium. This study used capacity loss data from the Dutch-Belgium Tesla Forum, where Tesla owners provided their data $[50,53]$. This study state that average capacity remain after $270,000 \mathrm{~km}$ is around $91 \%$, and if the linear trend would continue, then the vehicle lifetime can reach around $820,000 \mathrm{~km}$. Lifetime of battery in cycles would be around 2100 cycles, with $0.2 \mathrm{kWh} / \mathrm{km}$ fuel efficiency.

However, on the other hand it has been found in the study of $30 \mathrm{kWh}$ variants of Nissan Leaf that it degrades at much faster mean rate $9.9 \%$ of $\mathrm{SoH}$ of the battery in a year [36]. Same study hypothesise the the significance of temperature in accelerated degradation due to lack of active battery thermal management system (BTMS) in Nissan Leaf compared to other electric vehicles [4]. It is also expected that in the future, thermal management systems will be enhanced from the active air liquid or PCM based cooling system to more advanced hybrid cooling systems which will make temperature related degradation almost negligible [62].

Cost of battery degradation under V2G arbitrage has been researched thoroughly by the several studies $[29,28,44]$. These studies concluded that the degradation cost of providing $\mathrm{V} 2 \mathrm{G}$ arbitrage are much higher than the benefits of the same considering electricity market prices and battery replacement cost. However, recently Uddin et al. [56] have carried out the most profound study in the field of $\mathrm{V} 2 \mathrm{G}$ and battery degradation considering the comprehensive battery degradation model based on experimental investigation. This study developed the algorithm that optimised the $\mathrm{V} 2 \mathrm{G}$ arbitrage strategy considering the battery degradation cost. It concludes that with such an lgorithm, it is possible to optimally balance the V2G storage and cycling degradation and such balance help decrease the degradation of the battery compare to scenario where there is no V2G. 


\section{Chapter 3}

\section{Methodology}

\subsection{System Description}

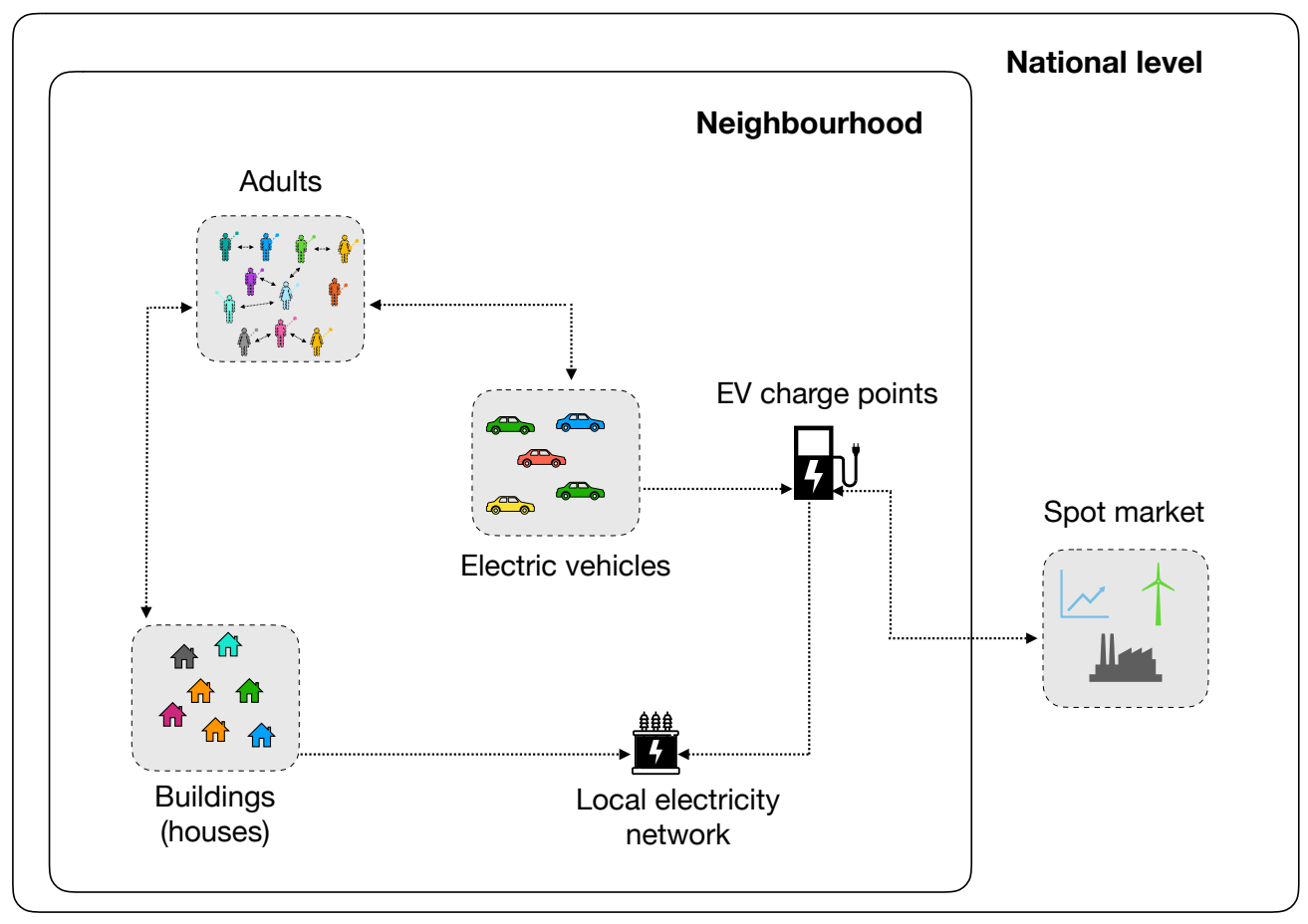

Figure 3.1: General structure of the model with key agents in the context of agent-based modelling

Based on fundamental concepts of agent-based modelling, SparkCity has been modelled in a way that it capture the generic elements of the energy and mobility system. In the context of agent-based modelling terminology, In SparkCity, agents are defined in a way that can be reused to model multi problems according to stakeholder needs. Moreover, it also provides facility of data storage and re usability for the model simulating different scenarios or problems.

SparkCity generic model contains agents such as building, family, adult, children, EV fleet and cables. However, for this study not all the agents are used to solve the problem at hand. As it can be seen in the figure 3.1, key agents that are used for this study are buildings,adults and EV fleet. In the SparkCity model, main 
agent ${ }^{1}$ is used for the modelling of the components that exist into environment or neighbourhood. Different agents can have access to this components by their needs. It is also used for defining the parameters of the population of agents ${ }^{2}$ and to access collective behaviour of the agent.

The version of SparkCity model that is used in the study can be visualised in the figure 3.1. It contains the key agents used for the study, their parameters and behaviour. It can be noticed that Spot market and electricity network is situated in the environment. As for the current study 'de Vliert' neighbourhood from the 's-Hertogenbosch city in the Netherlands is selected for the modelling. It has been used because it was already simulated with real network data and household load profiles in the model for the dissertation of [59]. However, as above mentioned study focuses on the detailed analysis of electricity network, few of the important components have been chosen to use for the simulation of the current study.

General idea of the model is that, neighbourhood has different types of households (building agent) in which adults are living and each adult owns an EV. These EVs can be charged according to different charging strategies at different types of charge-point exists in the neighbourhood. These charge-points are connected to electricity network in the neighbourhood.

\section{Overview of Characteristics in the Simulated Neighbourhood}

\begin{tabular}{||c|c||}
\hline Number of adults & 308 \\
\hline Numbers of EVs & 205 \\
\hline Apartments & 117 \\
\hline Terraced houses & 6 \\
\hline Detached houses & 63 \\
\hline Corner houses & 18 \\
\hline EV battery size distribution & $30-90 \mathrm{kWh}$ \\
\hline Percentage of adults working & $60 \%$ \\
\hline Workplace EV charging & $30 \%$ \\
\hline Workplace EV charge point power & $11 \mathrm{~kW}$ \\
\hline Private EV charge point power & $7.4 \mathrm{~kW}$ \\
\hline Public EV charge point power & $22 \mathrm{~kW}$ \\
\hline \hline
\end{tabular}

TABLE 3.1: Overview of characteristics in the simulated neighbourhood

\section{Bottom-up Modelling Approach}

In the model, EV users' charging costs depend on their characteristics of electric vehicle, charging location, driving behaviour (usage of vehicle) and spot market prices variation. Agent based-modelling uses bottom-up approach for the modelling of these characteristics and as it described above it uses generic agents from the SparkCity model. These agents are modelled in a bottom-up way to have a completely different rules and preferences which creates unique behaviour of each

\footnotetext{
${ }^{1}$ all the other agents resides in this agent. It can be considered as environment.

${ }^{2}$ collection of the similar type of agents
} 
agent. From these heterogeneity of the users system behaviour emerges which in turn influence the prices of spot market. In the upcoming sections how different agent's structure and behaviour is modelled in the study will be explained.

\section{Structure of the Agents}

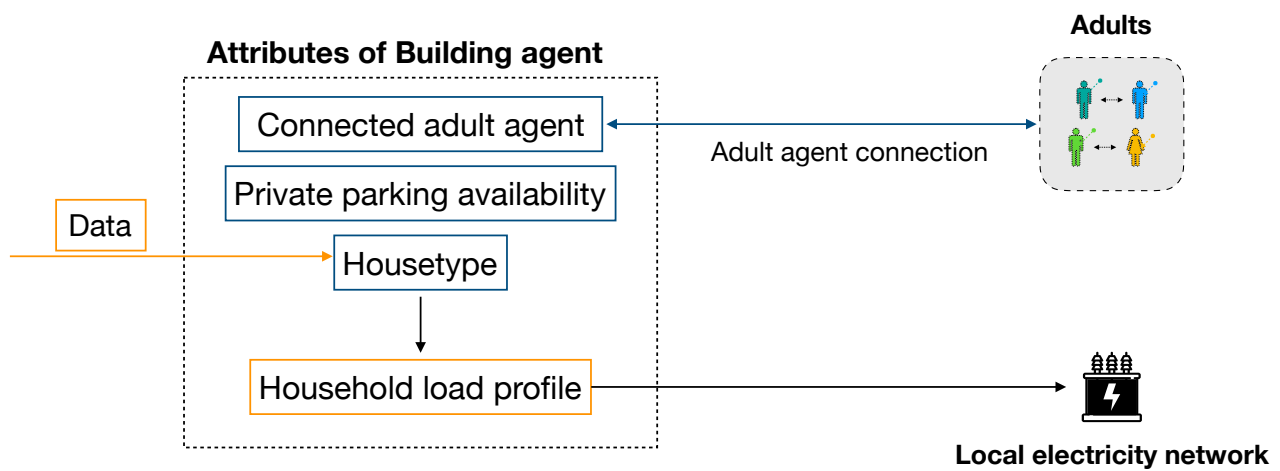

Figure 3.2: Attributes of the building agent

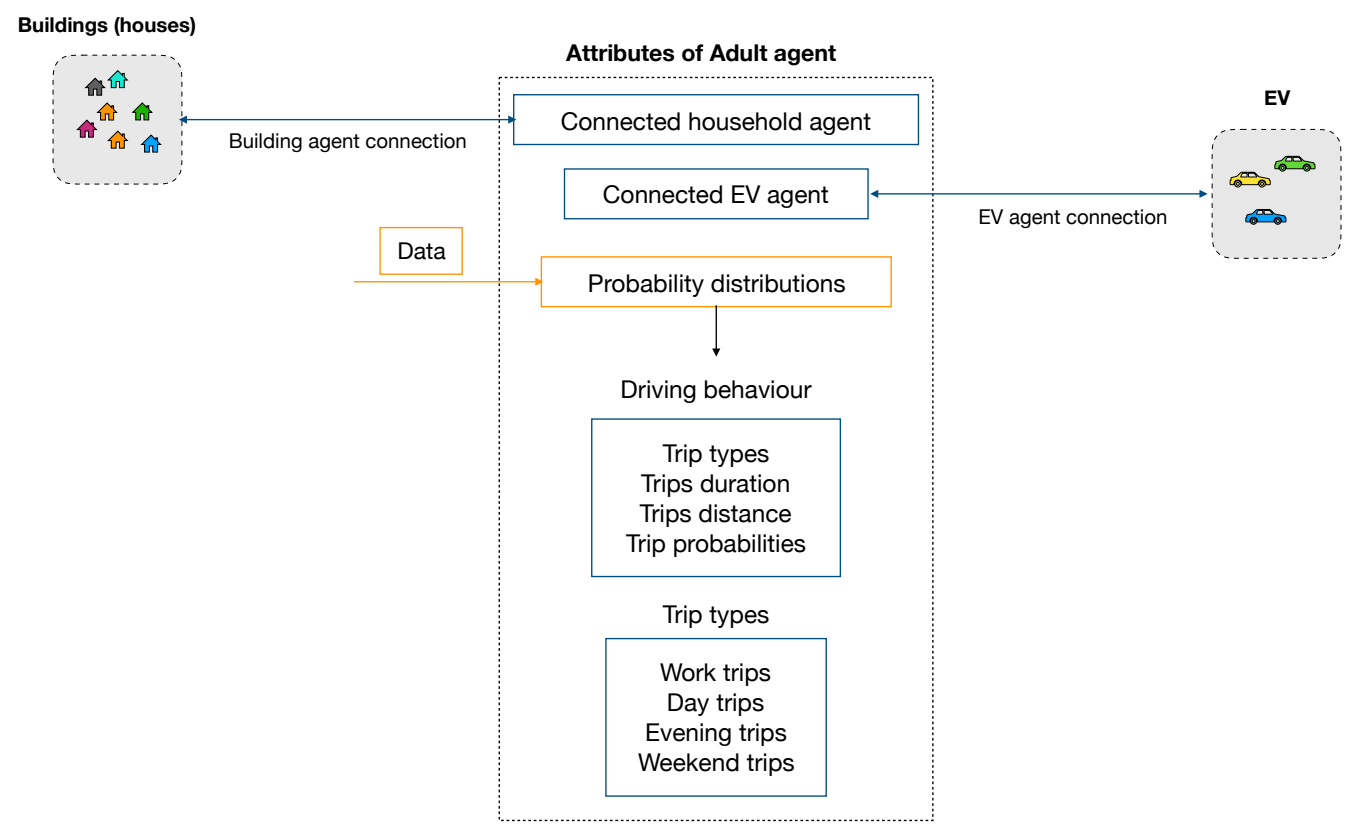

FiguRE 3.3: Attributes of the adult agent

\section{Software Implementation}

SparkCity model has been developed in the AnyLogic platform. It is multi-method modelling tool and supports agent-based, discrete event and system dynamics simulation methodologies [1]. It includes the graphical modelling language that 


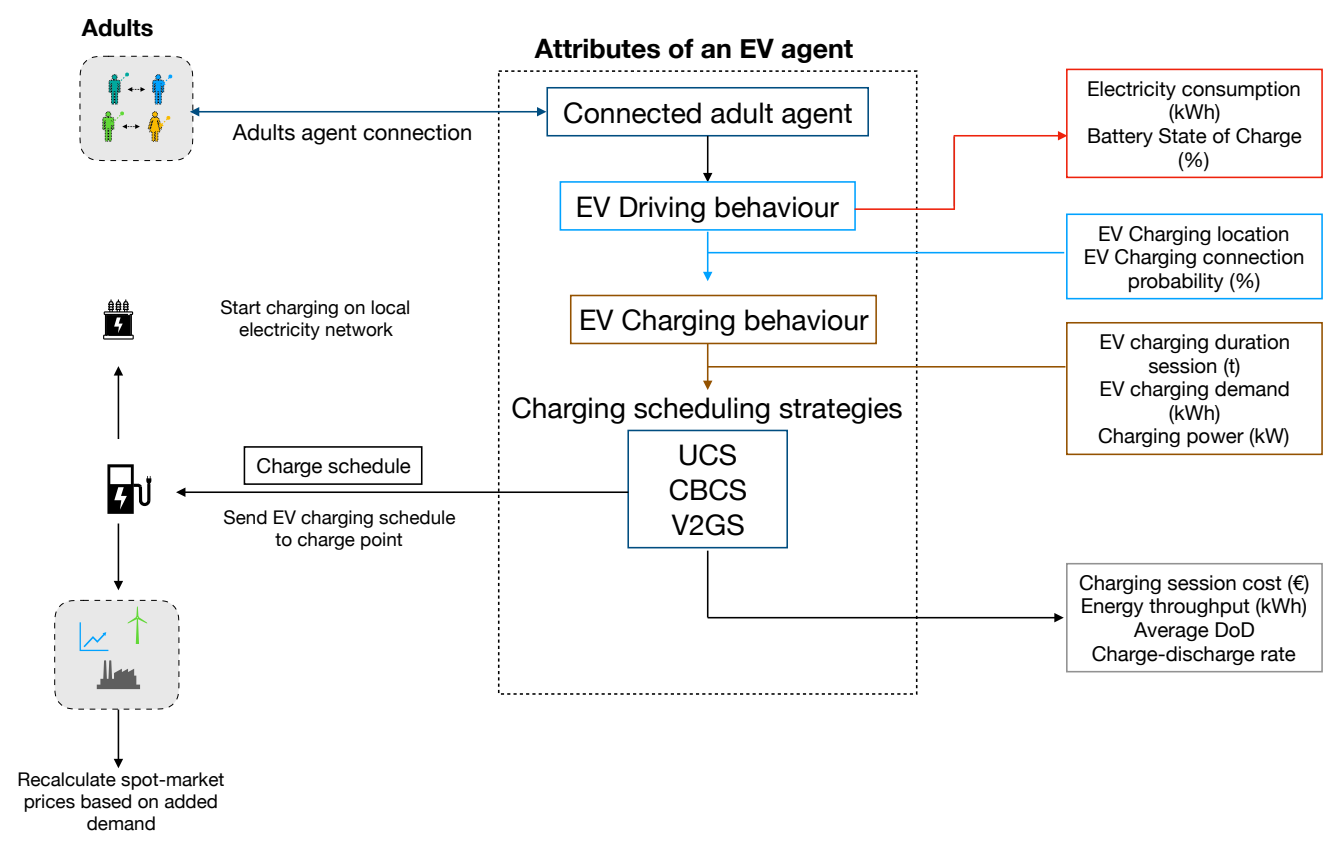

FIGURE 3.4: Attributes of the EV agent

allows user to extend the simulation with Java code. It is suitable for the agentbased modellers and non-programmers as it provides key features of object oriented programming as drag and drop graphical tools. Moreover, it provides useful agentbased capabilities, such as inspecting an individual agent of the model to know the what specific agent is doing at particular time during the simulation and how its behaviour or attributes are changing over the simulation run.

\subsection{Household Load}

The selected neighbourhood has various types of housing and parking possibilities. It consists of terraced houses, apartments, cornered houses and detached houses. Out of these different houses, detached houses and cornered houses possess private parking place.

It is important for the current study that household load profile should be unique and relating to the type of houses. However, real data from the households can not be used for the privacy issues. Construction of the household load profile used in the study is sourced from [59]. In mentioned study it is calculated based on historical electricity demand of residents in the Netherlands [2]. However, this data-set includes large numbers of residents types and their aggregated load profiles in which individual peak demand is level off because of random behaviour of residents.

For the construction of individual household load profile, two multiplication factors are used in the study. First multiplication factor depends on household type and second factor is random multiplier between 0.5 and 1.5. It is used to represent the random usage of electricity of an individual household. Individual electricity profiles of different household types can be seen in the figure. Electricity profiles constructs do not consider the weekend demand or seasonal variation. 


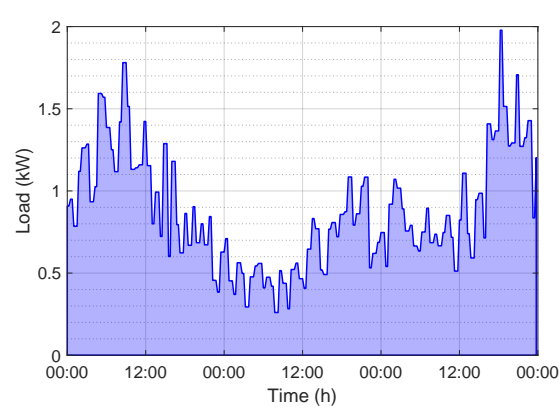

(A)

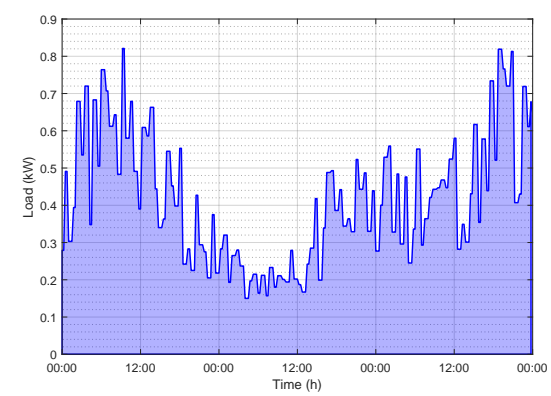

(c)

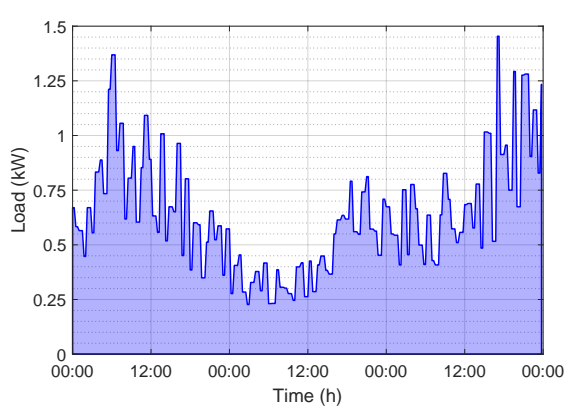

(в)

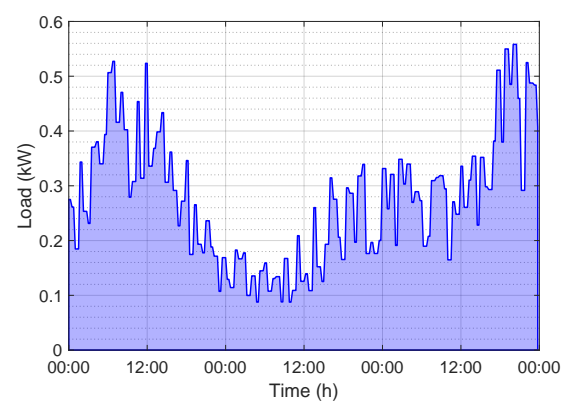

(D)

FiguRE 3.5: Different household load-profiles in the neighbourhood. (A) Detached house, (B) Cornered house (C) Terraced house (D) Apartment

\subsection{Driving Behaviour}

In this study, driving behaviour of the agent is very important characteristics to model. As charging cost of an agent depends on several characteristics that are related to driving and charging behaviour of the user, it needs to be modelled in a comprehensive manner. In the model, unique driving behaviour is created by assigning different types of trips to agent based on in-depth analysis of OViN (Netherlands National Travel Survey) data [49]. Main elements to define driving behaviour of the agent are trip type, trip duration, trip distances and trip probabilities. Trip types can be categorise in work trips, evening trips, weekend trips and day trips. Trip probabilities are mainly used for evening trips, weekend trips and day-trips. It is assumed that agents that are not working will make day-trips based on probability distributions.

Different types of distributions are created from the OViN data according to the needed important elements for defining the behaviour of the agent. It can be found in the appendix A. These distributions values are allocated to the population of agent adult. In this way, every agent will have unique trip departure time, duration of trip, trip distance and probability of trip. 


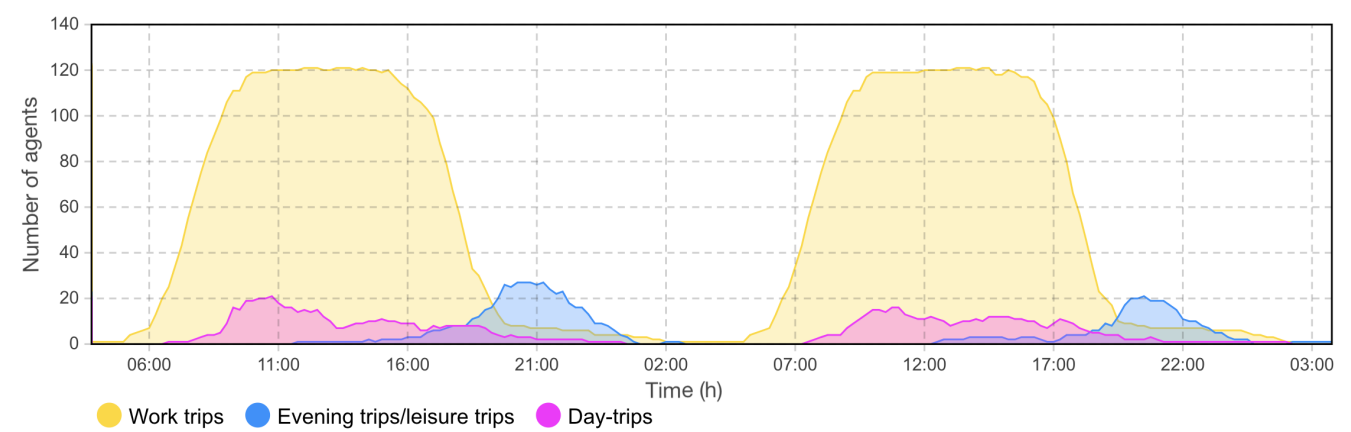

FiguRE 3.6: Number of adult agents making work-trips, evening/leisure trips and day trips in different point of time during two days

\subsection{Charging Behaviour}

Charging behaviour in the model is depending on the driving behaviour of the agent and availability of charge-point. Therefore, two state-charts ${ }^{3}$ are modelled in the EV agent which are location chart and charging chart.

Location chart have different states such as home, work and leisure where an EV can resides. EV agent is moving in between these state based on driving behaviour of the connected adult agent. At different states it checks the availability of chargepoint and probability of charging. For instance, EV when parked at home checks whether connected adult agent has private parking place, if it is available then EV connects to the private charge-point in the charging chart.

If connected adult agent has no private parking place, it will try to connect to public charge-point. However, connection to private charge point depends on the EV's range left, which can be categorise in upper limit, middle limit and lower limit. Upper limit range has lowest probability of connecting to charge-point and lower limit range has highest probability of connecting to charge-point. These probabilities can be found in table.

\subsection{Charging Strategies}

In the neighbourhood several EV users are connecting to charge point in different point of time. When an EV user connects to charge point in the neighbourhood, charging constraints are collected by the connected charge point. These charging constraints are duration of charging session $(\mathrm{h}$ ),rated charging power of the charging point $(\mathrm{kW})$, desired battery capacity at the end of the charging session $(\mathrm{kWh})$ and minimum battery capacity $(\mathrm{kWh})$.

Duration of charging session $(\mathrm{h})$ is calculated as the difference between the connecting time to charge point and time to initiate next trip. As time to next trip is based on driving behaviour of the EV user, it is possible to overrule the duration of charging session by the including probability of rule-based decision. It is assumed

\footnotetext{
${ }^{3}$ state-chart is graphical tool available in AnyLogic (platform) library. It facilitate to model the state of the agent in the context of spatial, temporal or both.
} 
that in such case EV user will not hold the right of optimised charging costs and will be penalised. However, penalty charge is not modelled in the current research.

As per the assumption described before, charge point sends above mentioned constraints to the aggregator who will optimise the charging schedule of an EV based on strategy described below.

\subsubsection{Vehicle-to-Grid Strategy (V2GS)}

From the literature review of profit optimised charging strategy especially in the context of $\mathrm{V} 2 \mathrm{G}$, optimisation of single EV trading at spot market has been formulated with backward induction algorithm. The problem formulation is mathematically represented as follow:

$$
\begin{gathered}
U^{o p t}=\max _{a_{t} \in\left\{c_{p}, 0,-c_{p}\right\}} U(\vec{a}) \\
U(\vec{a})=-\sum_{t=1}^{T} p_{t}\left(a_{t}\right)+V(x) \\
b_{\text {init }}+\sum_{t=1}^{T} a_{t}=x \\
b_{\text {min }} \leq x \leq b_{\text {cap }} \\
x \geq b_{\text {des }} \\
b_{\text {min }}=0.1 \cdot b_{\text {cap }}
\end{gathered}
$$

Where,

- $\vec{a}$ : The vector which contains the chosen action for each time step

- $c_{p}$ : Rated charging power for the connected EV

- $a_{t}: c_{p}$ (charging); $a_{t}:-c_{p}$ (discharging); $a_{t}: 0$ (not charging or discharging)

- B: Battery state of charge (state space)

- $p_{t}$ : Spot market price at time step $\mathrm{t}$

- $b_{c a p}$ : Electric vehicle battery capacity in $\mathrm{kWh}$

- $b_{\min }$ : Minimum allowed battery state of charge in $\mathrm{kWh}$

- $b_{\text {init }}$ : Initial value of battery state of charge in $\mathrm{kWh}$ when an EV connects to charge point

- $b_{\text {des }}$ : Desired amount of battery level at the end of the charging session

- $T$ : The set of time steps 
- $V(x)$ : Function represent the battery state of charge at the end of charge session

After formulating the problem mathematically, main constraints will be explained. Under the V2G strategy EV agent will sell or buy electricity based on aggregator's prices which reflects the prices of spot market. It will sell electricity when the hourly prices on the market is higher and will buy it when there is lower hourly prices. However, such strategy is not simple and utility of the vehicle is also important for the user. Taking that into consideration utility function has been defined as equation 3.2. In equation 3.2, $V(x)$ has been defined as the remaining battery state of charge at the end of charge session. It needs to meet the demand of the user at the end of the charging session, for that constraint in the equation 3.5 is proposed.

\section{Implementation of Backward Induction Algorithm}

Backward induction algorithm was used for the optimisation of the problem, which use discrete steps or states for the optimal decision. It represent Markova decision structure [35], which state that agent observes the economics of the feasible state $\mathrm{B}$, at time step $\mathrm{t}$ based on which it choose action a. For that, in the present study state space has been used to represent the battery state of charge.

State space represent the battery state of charge. Actions such as charging, discharging or do nothing takes the value of rated charging power for the connected EV. It represent the value of discrete step that algorithm takes into account to optimise the charging strategy. It should be noted that as battery state space is depend on the value of rated charging power, it changes every-time with the connected EV's initial SOC and rated charging power of charge-point.

It should also be noted that backward induction algorithm as discussed before is can also be represented and solved as shorted path in directed acyclic graph. In figure 3.7, such graph is presented for different charging strategies. However, UCS and CBCS doesn't follow the same optimisation problem and technique but for the purpose of comparison, path of these charging strategies has been presented.

Graphs presented in figure 3.7, decision paths have been presented with values given to it. Allowed paths are represented as orange and non-allowed paths are presented with black lines. It can be noticed that in UCS and CBCS, downward paths are not allowed because of uni-directional charging only. In CBCS, only upward and straight paths are allowed while in UCS, only upward paths are allowed.

Algorithm has been implemented in the EV agent of SparkCity model in AnyLogic. Action charts have been used for the algorithm implementation. When EV connects to the charge point, it triggers the V2G charging schedule in the platform environment and schedule is calculated based on input data provided. However, these input data needs to be transformed before feeding into the backward induction algorithm.

Transformation of the data is done in a way that it fulfils the requirement of directed acyclic graph (DAG). This requirement needs input data to be transformed as a graph presented in figure 3.7. From the figure, it can be visualised that all the possible paths are represented with the constraints into account. Here, state space of battery is represented as nodes in the DAG terminology. These nodes are the connected to each other with edges which has value of spot market prices. Upward 
edge has positive value as it charge the battery, while downward edge has negative value as it discharge the battery for which an EV get paid.

Implementation of the backward induction algorithm have been done in AnyLogic with actionchart. Firstly, it generate nodes based on input data, store this nodes in the vector of the node size in a way that it is directed towards the possible connected nodes. Edges connect these nodes and as it explained before gets the value of spot-market price at specific hour. Then matrix is created based on numbers of nodes and values of edges fill the matrix according to connected nodes.

\section{Time-steps}

During the implementation of algorithm it has been found that, hourly time-steps are not feasible as it gives huge discrepancy with higher rated charging power in matching the desired SOC of the connected EV. It can be understand clearly by visualising the figure 3.7. As discussed before algorithm uses discrete step and depends on the charging power, with higher charging power, the gap between desired SOC and possible final step of discrete step become bigger. To resolve this discrepancy, quarterly and 5-minute time steps are used.

\subsubsection{Cost Based Charging Strategy (CBCS)}

Cost based charging strategy, also known as smart charging or delayed charging and has numbers of variants based on stakeholder involvement. However, in this study simple cost-based charging strategy has been used. Figure 3.7 represent the cost based charging dispatch scheme.

It is possible to use backward induction algorithm for cost based charging strategy, by reducing the chosen actions $\vec{a}$ to charging and do nothing in equation 3.1. However, in this study, iteration method based optimisation algorithm is programmed as formulated in the dissertation of [34].

Implemented algorithm takes into account the spot market prices, duration of charging session, battery initial and desired SOC, and rated charging power for the optimisation. In an iterative process, most optimal hour is chosen to fill the charge schedule. Starting from the first iteration, it schedules the hour with cheapest price available. Scheduled $\mathrm{kWh}$ in hour is based on rated charging power of the charge-point. Optimisation continues until battery capacity is full or reached to desired SOC. 

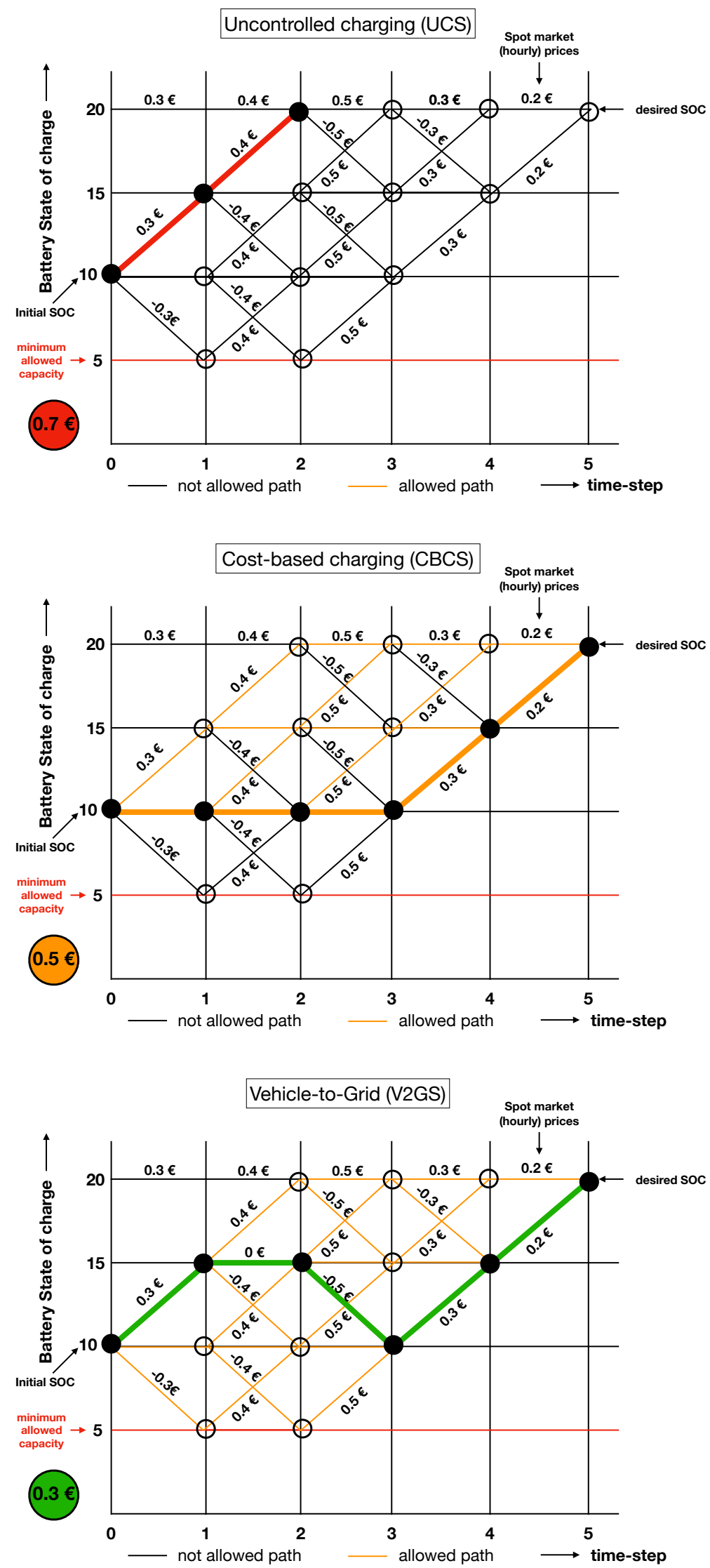

FiguRE 3.7: Example of different charging strategies implementation, CBCS and V2G are the optimised charging strategies while UCS is uncontrolled charging. 


\subsubsection{Uncontrolled Charging Strategy (UCS)}

Uncontrolled Charging Strategy (UCS), also known as the normal charging or dumb charging is used in the study as baseline charging scenario. In UCS, EV user connects to charge point and EV start to charge immediately until it reach the full capacity of the battery or desired SOC. Therefore there is no need of optimisation of the charging strategy. However, for the calculation of the charging cost and scheduling the demand on spot market, UCS schedule is important to program.

Dispatch scheme of UCS, can be visualised in the figure 3.7. In the terminology of DAG, as there are no allowed path except upward paths, it follows the most costliest path. So UCS is mostly expensive strategy for an EV user to charge their $\mathrm{EV}$.

\subsection{Spot Market}

Spot market has been modelled in the model to generate hourly prices by [34]. It has been created based on simple economic theory of supply and demand. However, electricity supply and demand on spot market are compared in a order of merit for every hour on the day ahead. The merit is determined by the SRMC of the generators and their capacity as can be visualised in the figure 3.8.

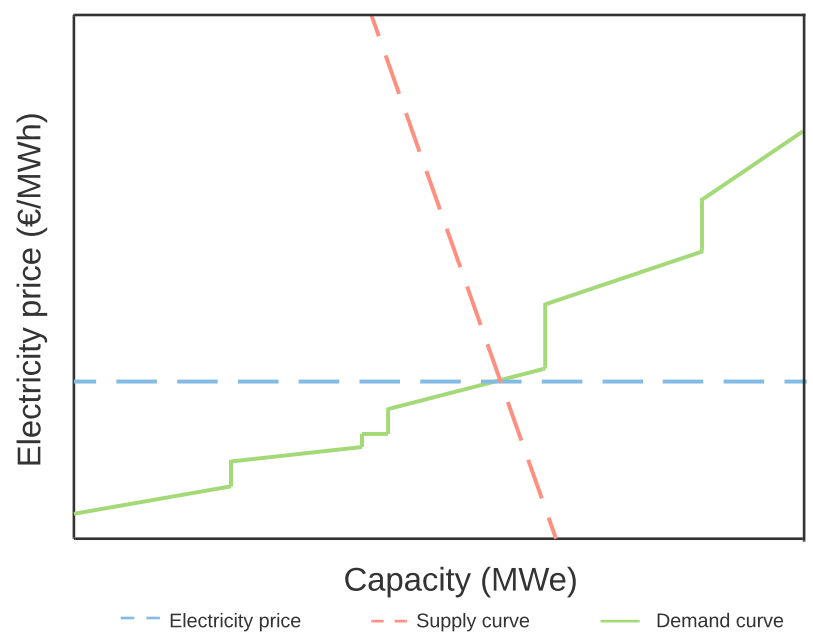

FIGURE 3.8: Merit-order with supply curve, demand curve and their intersection

As described before, to simulate the spot market prices, construction of supply curve and demand curve is vital. Supply curve for the simulated year has been constructed with fitted supply curve. It is based on researcher's findings of correlation between spot market prices and hourly average electricity demand [34]. Analysis of the prices have been done for day-ahead market in the Netherlands for 2016 .

In the figure 3.9 fitted curves have been presented. There are two fitted linear trend and one exponential trend as it can be visualised in the figure 3.9. y1 represent the fitted linear line for conventional generators lying between 5000 MWe and 15000 MWe. y2 represent the exponential trend in prices above 15000 MWe which relates 
to more expensive plants which are used for balancing. y3 represent the linear trend for renewable and coal supply capacity.

This graph also implies that how spot market prices will react according to generator's SRMC and installed capacities. It can be seen in the graph that if graph becomes steeper than the prices becomes more volatile and expensive. Adding more renewable into the system, supply curve is shifted to right side of the curve which lowers the price. On the other side, adding more demand, for example demand due to electric vehicles, will increase the spot market prices.

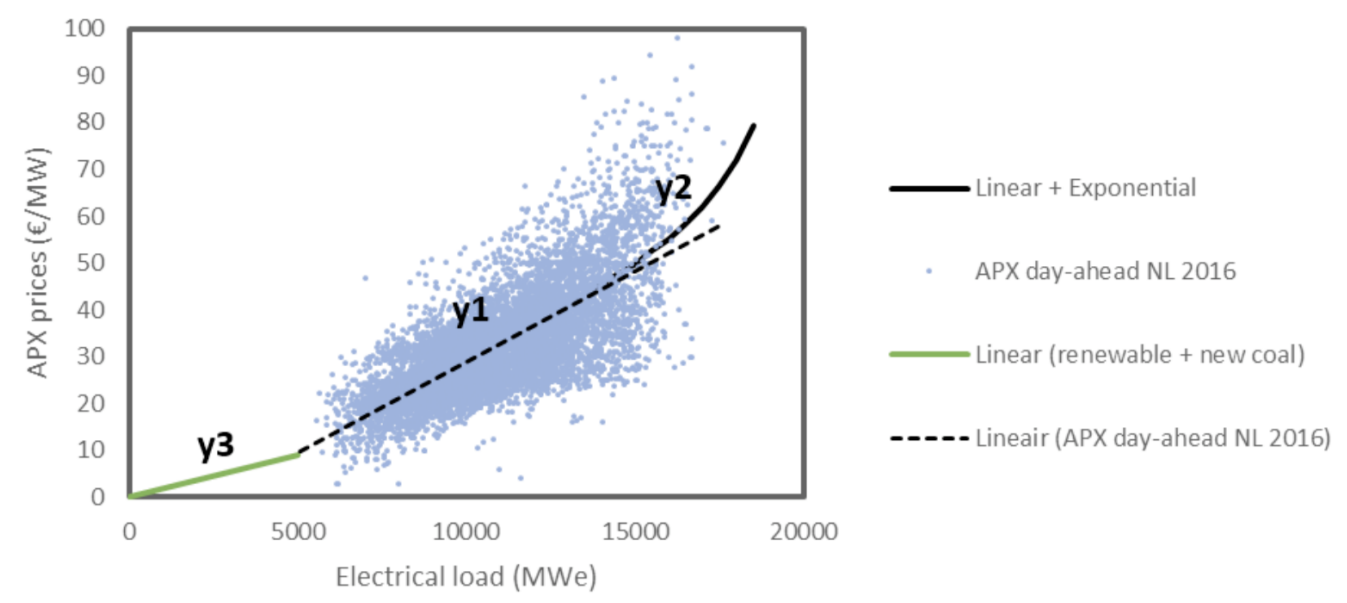

Figure 3.9: The APX day-ahead prices and fitted supply curves representing different generators and their capacity in 2016 .

Reprinted from [34]

\section{Input Data and Assumptions}

It is assumed that all the electricity consumption and generation in the Netherlands are traded on modelled spot market. All the conventional generators are available all the time during the year with fixed price. Spot market prices are based on the amount and type of installed capacity in the year that is simulated. In the model, installed capacity predictions have been used from ECN [41].

For the calculation of the spot market prices, hourly renewable energy production is needed in the simulated year. In the model, it is formulated with scaling of the hourly renewable production in 2016 to the installed capacity in the simulated year. In the model, national demand due to electrification will be increased every year with growth factor of $0.36 \%$. The average electricity demand at national level will also be increased or decreased with the EVs charging demand which is the focus of the research.

\subsubsection{Demand Shift on Spot Market Due to EV Charging}

Due to increased EVs charging demand, average demand is increased on spot market. As in the current model EVs represent the local neighbourhood, it needs to be scaled to the national market with a scaling factor. This scaling factor will scale the demand of EVs in the neighbourhood to the demand of EVs on a national 
level based on adoption rate. This demand shift due to EVs will influence the spot market prices every hour as discussed before.

The scaling factor depends on the ratio of the amount of EVs in the neighbourhood and the amount of cars in the Netherlands. As because there is more variation in the EV charging demand in neighbourhood than national level, average demand of the EVs in the neighbourhood can be considered and scale with a factor. As stated in [34], scaling factor, average charging load of an EV and demand shift can be formulated as below:

$$
\begin{gathered}
F_{s}=\frac{C_{n l}}{E_{s p}} \cdot E_{a} \\
C_{a v g}(t)=\frac{2 \cdot P_{a v g}(t)+C_{c l}(t)}{3} \\
D_{s}(t)=C_{a v g}(t) \cdot \frac{F_{s}}{1000}
\end{gathered}
$$

Where,

- $F_{s}$ : scaling factor used depending on the ratio between total cars in the Netherlands and total EVs in the neighbourhood

- $C_{n l}$ : Total amount of cars in the Netherlands

- $E_{s p}$ : Total numbers of EVs in the neighbourhood

- $E_{a}$ : EV adoption rate in the Netherlands

- $C_{\text {avg }}(t)$ : Average charging load of an EV currently charging in time t

- $P_{\text {avg }}(t)$ : Averaged charging load of an EV previously charged in time t

- $C_{c l}(t)$ : Charging load of an EV currently charging in time $\mathrm{t}$

- $D_{s}(t)$ : Spot market demand shift in time $\mathrm{t}$

The demand shift depends on two aspects. The average load of an EV currently charging and scaling factor. Total amount of cars in the Netherlands in equation 3.7 is around 8 million in 2018. However, the numbers of cars is growing with the growth factor of $1.65 \%$ a year. Adoption rate of EVs considered in the model is predicted by SparkCity model in the Netherlands [19]. Equation 3.7 takes into account the the variables mentioned above according to simulated year.

\subsection{Electricity Prices for EV Charging}

Electric vehicle charging costs at charging points are composed of several components and differ between different service providers [40]. As charging services is mainly provided by charge point operator or charge service provider, they charge the charging schedule based on different tariffs and schemes. For instance, either they have one time fixed cost for the charge session or they charge based on per kWh of electricity charged. Mostly, per kWh based charging costs are considered for the 
slow to medium charging of an EV. It also includes starting fee and subscription fees differ depending on the service provider.

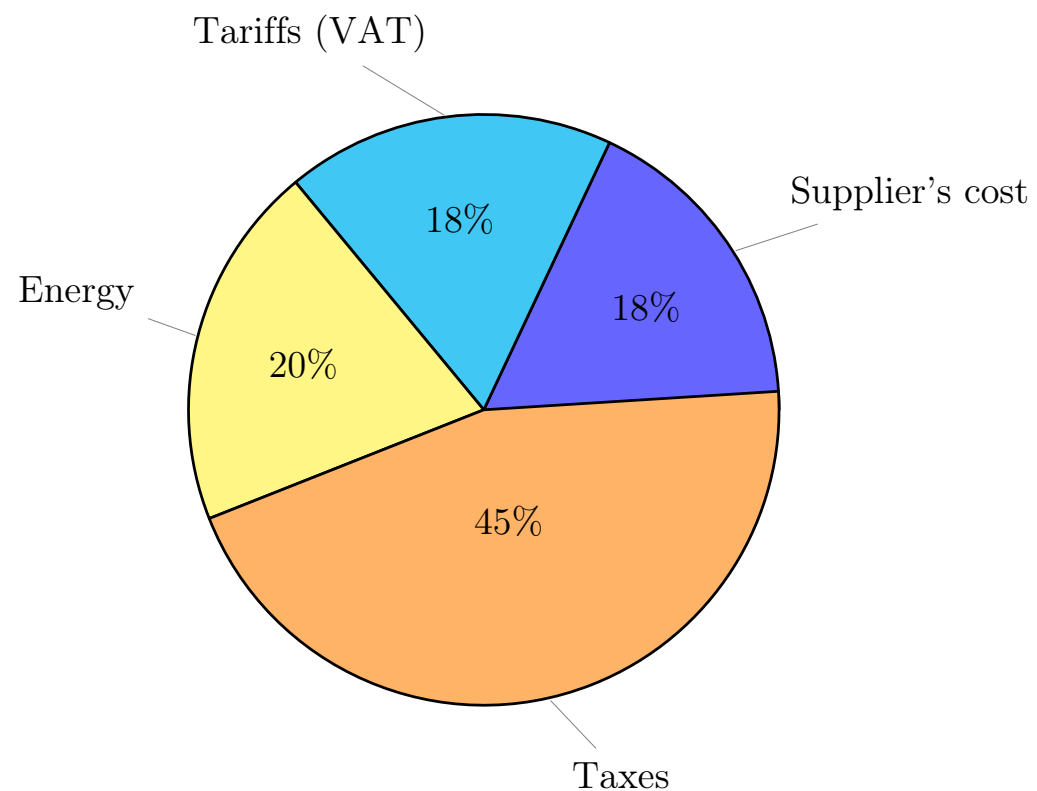

FIGURE 3.10: Composition of electricity prices for the EV charging as from the source [12] and discussion with expert in the Netherlands

In this study, per kWh based charging costs are considered and other costs related to service providers are ignored because of diverse and opaque composition of the costs for charging. After excluding the cost of service providers only electricity prices are left to consider. Electricity prices are composed of the wholesale energy price, energy tax, supply costs, network costs and value added taxes (VAT) [12]. Out of which energy tax and supply costs are fixed and charged per $\mathrm{kWh}$ of electricity consumption. Energy tax is $€ 0.10$ per $\mathrm{kWh}$ while supply costs is considered $€ 0.04$ per $\mathrm{kWh}$ (fixed cost). These prices are taken into consideration by discussing with expert in the Netherlands.

There are also network costs which are fixed and haven't taken into account. Currently the cost for grid connection depends on the size of the capacity. To get the bigger capacity user needs to pay more. However, in the future DSO will change this strategy and charge only for the congestion that user create in the grid.

\section{Taxation on V2G}

Currently V2G installations or activities are viewed from the consumer perspective in the context of taxes and tariffs in the Netherlands. It means all the electricity that is consumed is subjected to the dutch taxes and tariffs. However, flow of the electricity due to $\mathrm{V} 2 \mathrm{G}$ will be increased on the meter and it will be larger than the regular consumer. This increased flow will be used to provide the flexibility in the context of V2G arbitrage. But if all of these consumed and returned energy is billed as regular consumer, $\mathrm{V} 2 \mathrm{G}$ will not be profitable as because of higher energy flow and taxes and tariffs related to it [39].

But proposed solution to that currently in discussion in the Netherlands is net metering which would net out the electricity needed or used for the driving purpose 
and electricity used for the flexibility [57]. In this case, taxes and tariffs will only be applied to electricity used for the driving and the portion of loss. Therefore, proposed scenario is taken into consideration for the $\mathrm{V} 2 \mathrm{G}$ charging cost calculation in the current study.

\subsection{Battery Degradation Costs and Lifetime Economic Analysis}

As discussed before in 2, in this study battery degradation costs have been calculated with energy throughput model which consider the total energy throughput in the battery, EFC (Equivalent full cycleFs) due to varying DoD, and charge-discharge rate of the battery. It has been found during the literature review that the battery cycle life and DoD has logarithmic relationship for the lithium-ion batteries. Therefore, it can be said that with the decreasing DoD during the operation of the battery, battery cycles increase exponentially.

However it is important to consider the energy throughput or equivalent full cycles for the real representation of battery life, as these increased numbers of cycles represent the cycles at lower DoD which in turn converted to total transferable energy achieve the similar or slightly increased cycle life to deep cycling battery.

$$
\begin{gathered}
C_{v}=\frac{C_{b}}{2 \cdot L_{N} \cdot E_{v} \cdot D o D_{r e f}} \\
C_{b}=c_{b} \cdot E_{v}
\end{gathered}
$$

Where,

- $C_{v}$ : Battery degradation cost in $€ / \mathrm{kWh}$

- $C_{b}$ : Battery capital costin $€$

- $L_{N}$ : Battery lifespan in numbers of cycles in numbers

- $E_{v}$ : Total energy storage of the battery in $\mathrm{kWh}$

- DoD $D_{r e f}$ : Reference depth of discharge (standard condition)

- $c_{b}$ : Battery cost per $\mathrm{kWh}$ in $€ /$ per $\mathrm{kWh}$

For the calculation of degradation costs, it is assumed that the cost of degradation is zero if the battery cycle life due to driving plus V2G degradation exceed the vehicle life. Vehicle life in the Netherlands is considered approximately 18 years. For that lifetime cycles or total energy throughput needs to be calculated with V2G and without V2G. As the model will run on yearly basis for three different scenarios $(2019,2025$ and 2030), total energy throughput or equivalent full cycles has been considered the average value of these years. This yearly average values are multiplied with the vehicle life time to get the lifetime energy throughput with V2G and compared with the available battery life cycles.

Equation 3.10 is used for the simple calculation of the battery degradation costs per $\mathrm{kWh}$. Total cost of battery degradation per year can be calculate by multiplying the degradation cost per $\mathrm{kWh}$ to energy throughput due to V2G in a year. However 
during the process of calculating the degradation costs, it is realised the need for adding residual value for the batteries. In such calculation, difference between lifetime economic analysis of the battery with V2G operation and without V2G operation can be compared.

For this calculation, predicted battery pack prices and battery cycle life values are allocated over the years [3]. However, in the literature and real life battery cycle life predictions are very high [16], but for this study linear growth has been taken into consideration. In the new calculation, replacement year has been calculated with the average battery cycle usage with V2G

$$
\begin{aligned}
& L_{E F C}=L_{e x p} \cdot D o D_{a v g} \\
& Y_{b r}=\frac{L_{E F C}}{L_{V 2 G}} \\
& C_{b r}=c_{b r} \cdot E_{v} \\
& R_{v f}=0.2 \cdot c_{b r} \cdot E_{v} \\
& N_{b r}=C_{b r}-R_{v f} \\
& L_{n f}=L_{n e} \cdot D o D_{a v g} \\
& L_{v e}= \begin{cases}L_{E F C}-\left(L_{V 2 G} \cdot E_{l}\right), & \text { if } Y_{b r} \geq E_{l} \\
L_{n f}-\left(L_{V 2 G} \cdot\left(E_{l}-Y_{b r}\right)\right), & \text { otherwise }\end{cases} \\
& C_{e}=c_{e} \cdot E_{v} \\
& c_{l}=\frac{C_{e}}{L_{e f}} \\
& \left.R_{v e}=\left(0.5 \cdot c_{l} \cdot L_{v e} \cdot E_{v}\right)+\left(0.2 \cdot C_{e} \cdot E_{v}\right)\right) \\
& L_{e}=L_{E F C}-\left(L_{V 2 G} \cdot E_{l}\right) \\
& \left.R_{e}=\left(0.5 \cdot c_{l} \cdot L_{e} \cdot E_{v}\right)+\left(0.2 \cdot C_{e} \cdot E_{v}\right)\right) \\
& R_{d i f}=R_{v e}-R_{e}
\end{aligned}
$$




$$
\begin{gathered}
B_{t v}=B_{V 2 G} \cdot E_{l} \\
C_{V 2 G}=R_{d i f}-N_{b r} \\
N_{V 2 G}=B_{t v}-C_{V 2 G} \\
N_{a v}=\frac{N_{V 2 G}}{E_{l}} \\
C_{d}=N_{a v}-B_{V 2 G}
\end{gathered}
$$

Where,

- $L_{E F C}$ : Expected total equivalent full cycles (EFC) before replacement of battery with V2G in numbers

- EFC: Equivalent full cycle in numbers

- $L_{\text {exp }}$ : Expected total battery cycles at certain DoD value before replacement of battery with $\mathrm{V} 2 \mathrm{G}$ in numbers

- $D o D_{\text {avg }}$ : Average depth of discharge of the battery in the year

- $E_{v}$ : Total energy storage of the battery in kWh

- $L_{V 2 G}$ : Total V2G cycles over the life of vehicle in numbers

- $Y_{b r}$ : Number of years after battery replacement needed (due to $E_{v}<80 \%$ )

- $N_{b r}$ : Net replacement cost of battery in $€$

- $c_{b r}$ : Battery replacement cost per $\mathrm{kWh}$ in the replacement year in $€ / \mathrm{kWh}$

- $C_{b r}$ : Total battery replacement cost in the replacement year in $€$

- $c_{l}$ : Cost of of battery per cycle in $€ /$ cycle

- $L_{n f}$ : Expected total equivalent full cycles after replacement of the battery with $\mathrm{V} 2 \mathrm{G}$ (new battery) in numbers

- $L_{n e}$ : Expected total battery cycles at certain DoD value after replacement of battery with V2G (new battery) in numbers

- $E_{l}$ : Lifetime of vehicle (18.3 in the Netherlands) in numbers

- $L_{e}$ : Battery cycles left at the end of vehicle's life without V2G operation in numbers

- $R_{e}$ : Residual value of the battery at the end of vehicle's life without V2G operation in $€$

- $R_{v f}$ : Residual value of the battery at replacement year with $\mathrm{V} 2 \mathrm{G}$ in $€$

- $L_{v e}$ : Battery cycles left at the end of vehicle's life with V2G in numbers

- $R_{v e}$ : Residual value of the battery at the end of vehicle's life with V2G in $€$ 
- $R_{\text {dif }}$ : Residual value difference of V2G operation and non V2G operation at the end of vehicle's life in $€$

- $B_{V 2 G}: \mathrm{V} 2 \mathrm{G}$ benefit per year (without degradation cost included) in $€$

- $B_{t v}$ : Total V2G benefit over the life time of vehicle in $€$

- $C_{V 2 G}$ : Total cost of $\mathrm{V} 2 \mathrm{G}$ over the vehicle's life time in $€$

- $N_{V 2 G}$ : V2G net benefit over the vehicle's life time in $€$

- $N_{a v}$ : V2G net annual benefit in $€$

- $C_{d}$ : Cost of degradation per annum $€$

- $c_{e}$ : Expected cost of battery per kWh at the end of vehicle's life $€ / \mathrm{kWh}$

- $C_{e}$ : Expected cost of battery at the end of vehicle's life in $€$

- $L_{e f}$ : Expected battery equivalent full cycle numbers in the scrap year of vehicle (end-life) in numbers 


\section{Chapter 4}

\section{Results}

Based on the methodology and input data described in the previous chapter, results have been generated. This chapter includes a detailed analysis of the results and validation method used to compare the results based on the input data and scenarios in the model. In the first section, Influence of different charging strategies (UCS, CBCS, and V2GS) on the national energy system and local electricity network will be compared with national average electricity demand, average spot market prices and local electricity load for the year 2019, 2025 and 2030. This section will be followed by the illustration of charging costs and monetary benefits of V2GS concerning other charging strategies already discussed. Section 3 will include the degradation costs and net V2GS benefit analysis.

\subsection{Influence on National Energy System}

The underlying modelling approach in this study includes generation of hourly spot-market prices based on average electricity demand and supply capacities in the Netherlands. With the rise in EV adoption, EV electricity demand or supply (in case of V2GS) will highly influence the average electricity demand at spot market and subsequently the spot market prices. Furthermore, the penetration of more renewable energy supply capacities also influence the spot market prices. Therefore, it is important to analyse and elaborate on the Influence of EV electricity demand and more renewable on spot market average electricity demand and average prices in different years. Moreover, this study takes into consideration the feedback of charging prices of EVs based on different strategies on spot-market, which means EVs starting their charging earlier at lower market prices will increase the overall market prices and eventually it influence the charging costs of EVs connecting in a later time. Three yearly scenarios 2019, 2025, and 2030 have been analysed for the comparison of system influence and individual monetary benefits. Several yearly scenarios have different EV adoption rate and Renewable penetration rate based on predicted data, to assess the impact of more EVs and renewable on spot market demand and prices.

To illustrate the impact of EV adoption in the neighbourhood, percentage of EV allocation to the household (or/and adult)is varied from 2\% in 2019 (current adoption rate in the Netherlands), $20 \%$ in 2025 to $50 \%$ in 2030. It is based on the percentage predicted by the SparkCity model in the previous research. These percentage resembles the numbers of households or adults owning an EV in the neighbourhood. 
Influence of renewable on spot market prices has been captured by varying the percentage of renewable penetration in the system. It is varied from $22 \%$ in 2019 , $51 \%$ in 2025 to $65 \%$ in 2030 (based on ECN prediction [41] in the Netherlands). The simulation has been run over the year as well as for the winter and summer month to capture the Influence of solar and wind production separately on spot market prices. The month of January and May is selected for the winter and summer season respectively, because of high wind power production in January and high solar production in May in the Netherlands.

\subsubsection{Demand Shift on the National Level Due to Different Charg- ing Strategies}
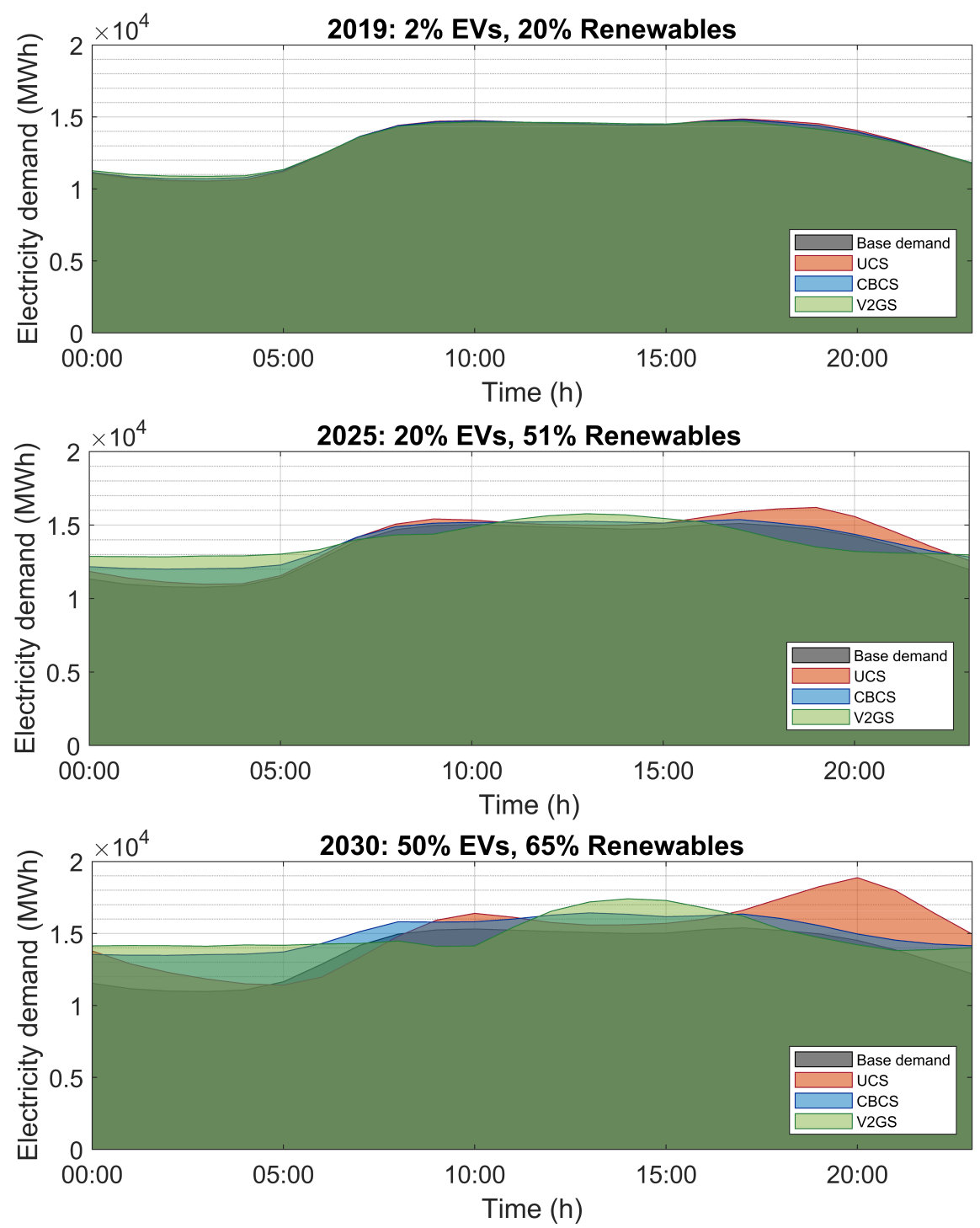

FiguRE 4.1: Hourly average demand shift due to charging of EVs on national compared with average demand of the Netherlands 
Fig 4.1 shows the average electricity demand for the formulated scenarios. There are four different area graph curves presented to show the difference in electricity demand due to different charging strategies concerning baseline demand. Baseline demand is hourly average electricity demand in the Netherlands in the respective years. In this study, the hourly average demand of 2016 is used as baseline demand, and it is increasing with the $0.37 \%$ growth factor over the year [41].

In 2019, 2025 and 2030 average demand increase per hour is $0.4 \%, 3.6 \%$ and $8.73 \%$ respectively. In 2019, increase in demand due to EV charging is very minor as it can be visualised in figure 4.1 Most important difference between UCS, CBCS and V2GS scenarios is that demand increase in the normal charging scenario increases the peak demands during the morning and evening time, in smart charging it increases valley demand until 2025, but after 2025 peak hour demand is increased because of more EV adoption. While In V2GS scenario, it increases the valley demand during the night. During the day, V2GS demand increases because of meager prices due to high solar PV production (with more renewable penetration) and during the morning and evening, with the capabilities of energy feedback V2GS decreases the demand. Although V2GS mostly flatten out the demand curve with the rise in EV adoption, on the later stage, it increases the demand in the middle of a day with more EV adoption. It is suitable for the energy system with high solar capacities in the future. As during the day time most vehicles are parked at work location, it provides huge potential to store residual solar production and later to utilise it in peak time.

\subsubsection{Influence on Average Spot Market Prices Due to Different Charging Strategies}

After analysing the effects of different charging strategies on hourly average demand over the 2019,2025 and 2030, these effects can be easily linked to the Influence on spot market prices because of its direct co-relation with hourly electricity demand.

In the figure 4.2 influence of different charging strategies (UCS, CBCS, and V2GS) on average spot market prices for the year 2019,2025 and 2030 have been compared with the prices without the Influence of EV charging. Here base prices represent spot market prices with the baseline demand without EV charging demand. It can be observed that average base prices have decreased in the year 2025 compared to 2019, and further decreases even more in the year 2030. The reason for the decrements in the average spot market prices is the higher renewable energy penetration in the respective years. According to the merit order effect ${ }^{1}$, marginal cost generators primarily decides the price of the electricity at the spot market. With the increase in renewable capacities, expensive generators are pushed to the right of the merit order, and prices are decreased for the same electricity demand. It can be observed that spot market prices are going very low in the day time during the year 2030, it is because of the very high installed capacities of solar PV and deficient demand during the same time.

After analysing average hourly prices at spot market prices, volatility is also measured for different scenarios with an average root mean square error (RMSE). Price volatility is essential term while analysing the cost-effectiveness of the different

\footnotetext{
${ }^{1}$ merit order is a way of ranking available sources of energy, especially electricity generation, based on ascending order of price together with the amount of energy that will be generated [33]
} 


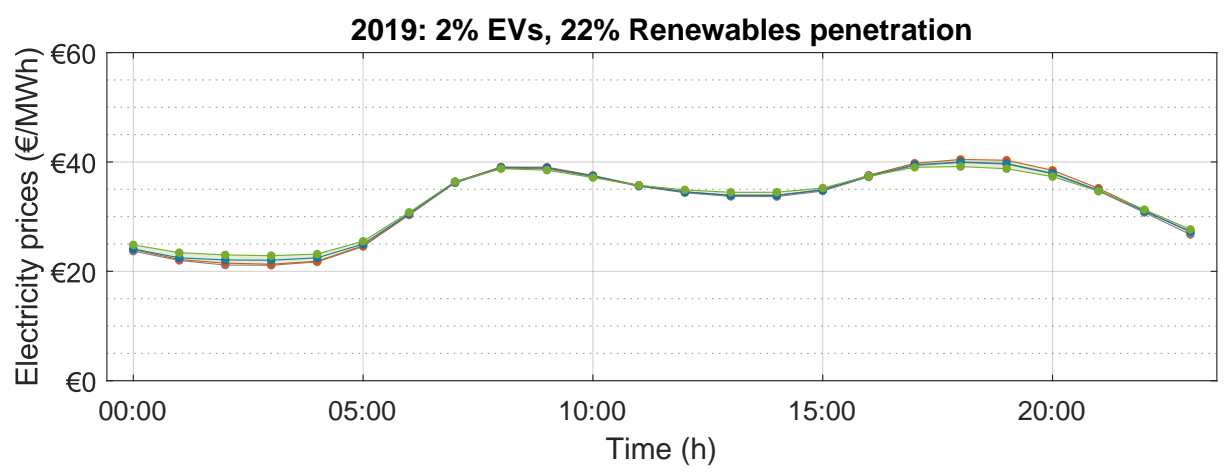

2025: $20 \%$ EVs, 51\% Renewables penetration

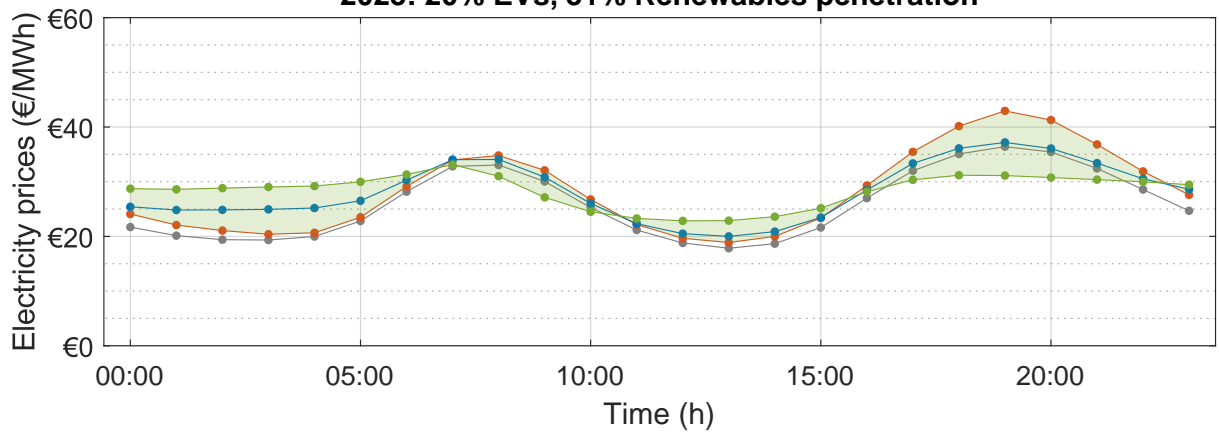

2030: $50 \%$ EVs, $65 \%$ Renewables penetration

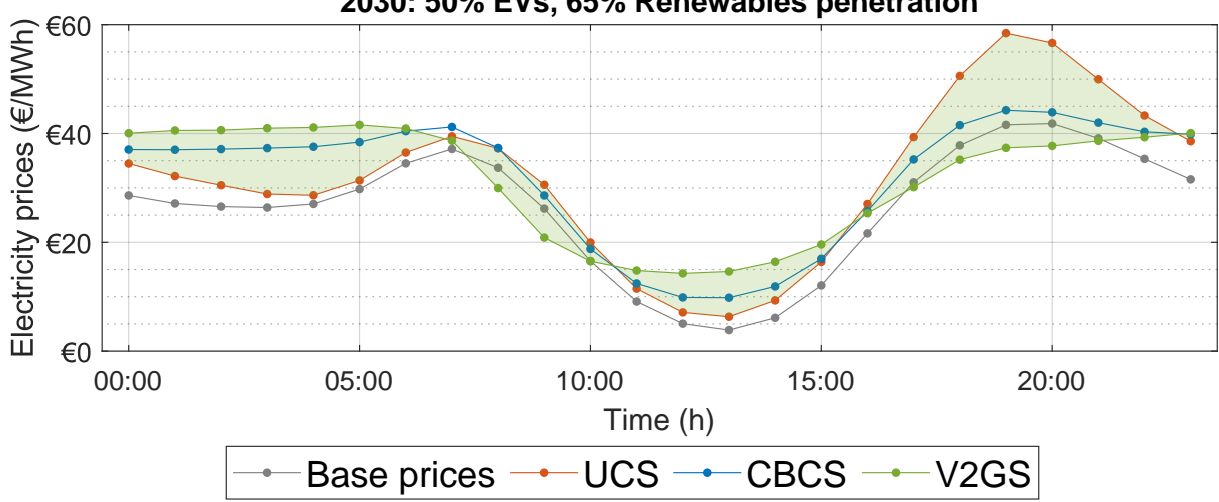

Figure 4.2: Average market prices for UCS, CBCS, V2GS and the prices without the demand shift due to charging

cost-based charging strategies (CBCS and V2GS). It is calculated by taking the average of distances between hourly prices of the day and the daily average price. It is noted that with higher renewable percentage, volatility in the average spot market prices is increased. Average RMSE is highest in the year 2030 with UCS. As it is already mentioned before, it is because of high solar production in the day time, which decreases the price drastically and negligible EV charging demand during this time increase the volatility.

$$
R M S E=\frac{1}{N} \sum_{i=0}^{N} \sqrt{\left(d_{i}^{a v g}-p_{i}\right)^{2}}
$$

Where,

- $N$ : Amount of hours in a year 
- $p_{i}$ : Spot market price in the $i^{\text {th }}$ hour

- $d_{i}^{\text {avg }}$ : Average spot market price of the corresponding day

In 2019, average prices are increased marginally because of lower EV charging demand due to low EV adoption (2\%). In 2025, the volatility of the UCS prices is increased, which is because of uncontrolled EV demand. On the other hand, it can be noticed that V2GS is flattening out the curve of the prices and decreasing the volatility, which makes the electricity market more liquid. However, In 2030, even with higher EV adoption (50\%) and V2GS scenario prices are more volatile compared to 2025. It signals the need for more work EV charge-points or public charge-point that can be used in the day-time. So that EVs can charge their batteries during the day time with meager prices and feed it back when there is peak demand.

It can be easily observed that with CBCS and V2GS valley prices increase in all three scenarios (years). The area filled by light green colour, indicate the prices increment and decrements due to valley filling and peak shaving respectively by V2G compared to baseline EV charging demand.

\subsubsection{Influence on Local Electricity Network Due to Different Charging Strategies}

In figure B.1 hourly average loads on the local electricity network is presented. Increase in load on the electricity network in the year 2019 is relatively minor with all charging strategies. However, in 2025 and 2030, there is a significant increase in load on the local grid. As it can be seen in 2025 and 2030, V2G has load peaks in the night time and day-time (noon) when there is not much house load on the grid. $\mathrm{V} 2 \mathrm{G}$ also provide local supply during the peak time (early morning \& evening) which surge the load drastically and goes negative in the morning in 2030.

\subsection{Monetary Benefits}

After running the simulation on yearly basis and based on input data (emergent behaviour) discussed in the previous chapter charging costs for different users and different strategies have been generated. V2G monetary benefits, which is the goal of this research is calculated by taking difference between V2GS charging costs and other two charging strategies. It is the profit that EV user gets after providing V2G at electricity market. As the model used before 15-minute time-step profit maximisation algorithm for V2GS, there was a discrepancy in the wanted $\mathrm{kWh}$, scheduled $\mathrm{kWh}$ and charged $\mathrm{kWh}$. It was solved by the increasing time-step to 5-minute.

\subsubsection{Selected EV users for the Comparison of Monetary Benefits}

In the model, there are $200 \mathrm{EV}$ users making daily trips based on data provided. However, it is important to select few of the different EV users based on their driving pattern, charging pattern and EV characteristics. These are the important factors to consider that influence the charging costs and monetary benefits. Moreover, anylogic, a platform that has been used for the modelling and simulation for the 
research provides flexibility to define behaviour for both the individual agent (EV user) and collections of the agent (EV users).

Table 4.1 elaborate the different EV users characteristics. These EV users have been defined or selected based on the persona creation method. Although,method of persona creation involves highly sophisticated methodology and empirical data sets to define the personas, it mainly identifies the similar behaviour or characteristics trends in the people and boils it down to the few user-like personas [46].

In the selected EV users, User 1,2 \&3 are working users in the neighbourhood. So these users have high daily driving distances compared to User $4 \& 5$ as they are not working and mainly makes day-trips. Moreover, User $4 \& 5$ are connecting to public charge-point few times a week. User 4 connects to public charge-point for the overnight charging and User 5 connects to the charge-point in a day-time.

\begin{tabular}{|c|c|c|c|c|c|}
\hline & User 1 & User 2 & User 3 & User 4 & User 5 \\
\hline EV Battery capacity (kWh) & 90 & 75 & 60 & 40 & 30 \\
\hline Charge-point availability & Private \& Workplace & Private & Workplace & Public & Public \\
\hline EV Charging power $(\mathrm{kW})$ & $7.4 \& 11$ & 7.4 & 11 & 22 & 22 \\
\hline Daily driving distance $(\mathrm{km})$ & $140-160$ & $100-120$ & $60-90$ & $20-30$ & $15-20$ \\
\hline EV Plug-in duration ${ }^{23}$ (hours) & $18-20$ & $10-12$ & $8-9$ & $10-12$ & $4-6$ \\
\hline
\end{tabular}

TABLE 4.1: Specification of the EV users selected from the neighbourhood for the comparison of V2G monetary benefits

\subsubsection{Weekly SOC Distribution of EV Users under UCS, CBCS, and V2GS}

For the correct interpretation of the user behaviour SOC distribution chart has been created. It presents the SOC distribution of the selected EV users over a week. Although this study takes into consideration varying behaviour of the EV users based on data over the year, weekly SOC distribution is created to capture the effect of different charging strategies on different EV users on minimum time-series scale. Moreover, it includes charging location/ charging power, charging timing and plug-in duration of different EVs related to different users.

It can be observed in the figure 4.3 that under the baseline strategy EVs have lowest plug-in duration and highest duration sitting idle at full SOC. It is expected because of uncontrolled or immediate charging with baseline strategy. In baseline strategy, EV user connects to charge-point and ask for immediate charge of EV until its battery capacity is full. It has also lower connection time and usage of charge-point compare to other two strategies. With the CBCS, EV is charged during the most cheap hours in provided charging duration, which lengthen the plug-in duration and connection time to charge point. In V2GS, highest plug-in duration can be observed with highly varying SOC during the plug-in duration.

It can also be noted that EVs connected to public EV chargers have high depth of discharge (DoD), as charging power at public chargers are the highest compared to other charging locations. Moreover, User $3 \& 4$ have lowest battery capacity size amongst the other EV users. 
(a) UCS (baseline)

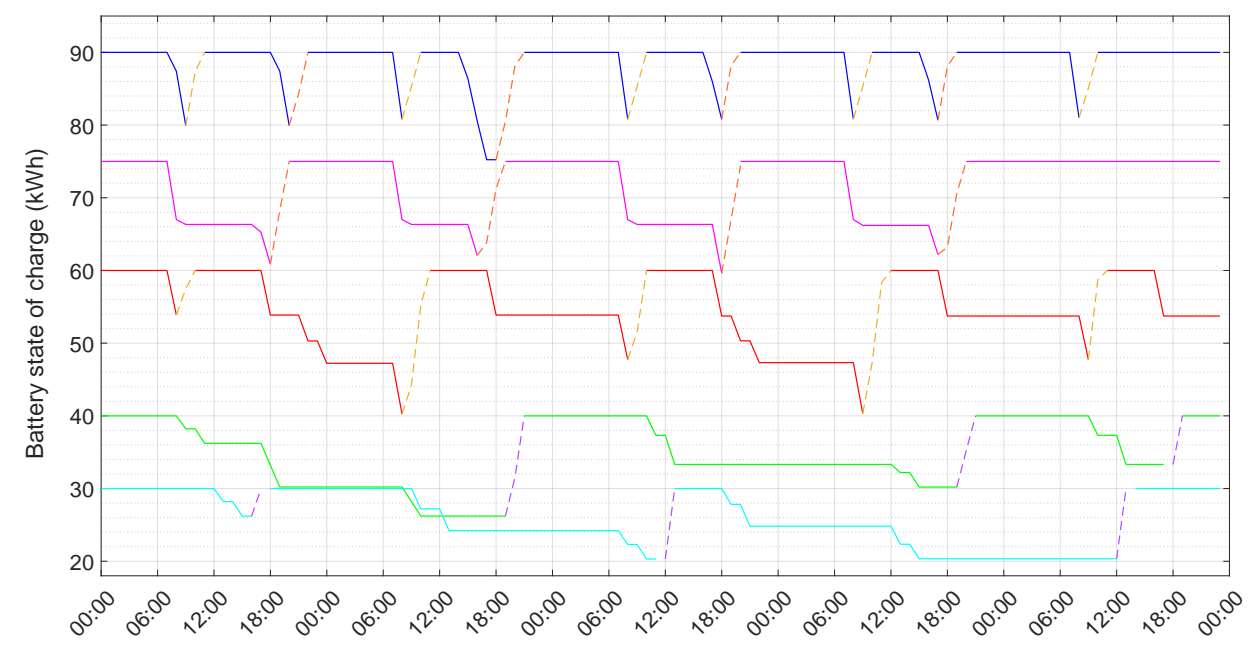

(b) $\mathrm{CBCS}$

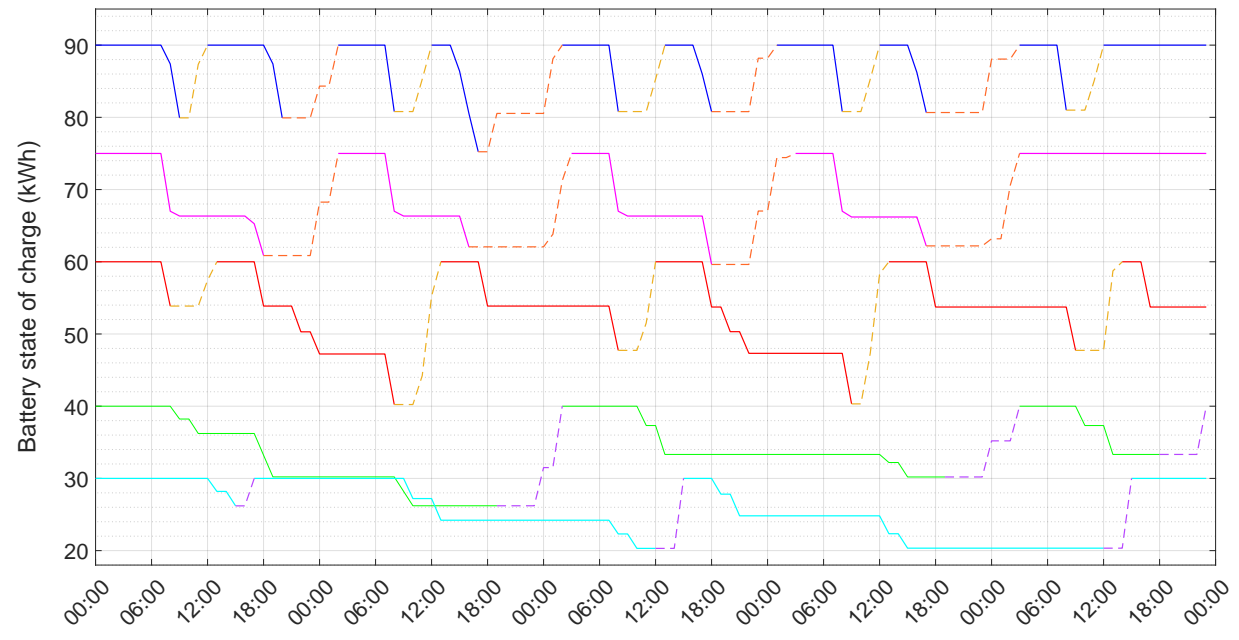

(c) V2GS

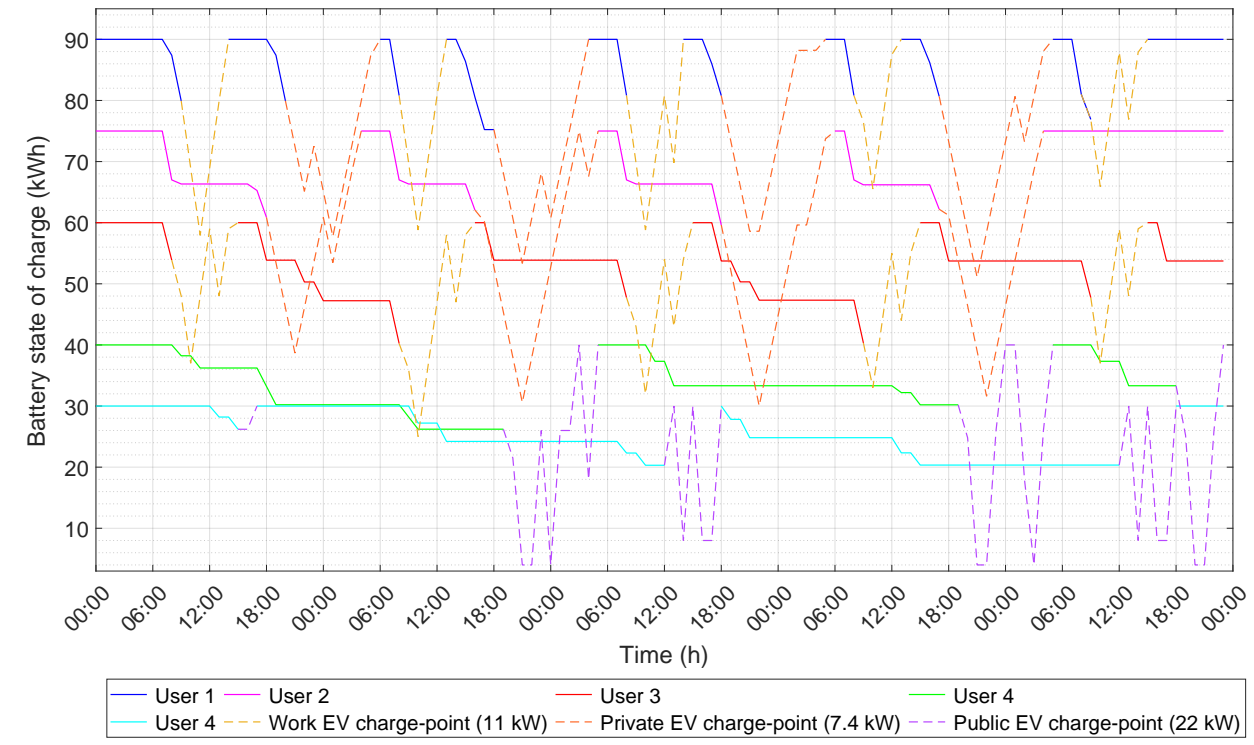

FIGURE 4.3: Weekly SOC distribution of different EVs (related to users) under different charging strategies 


\subsubsection{Battery energy throughput under UCS, CBCS and V2GS}
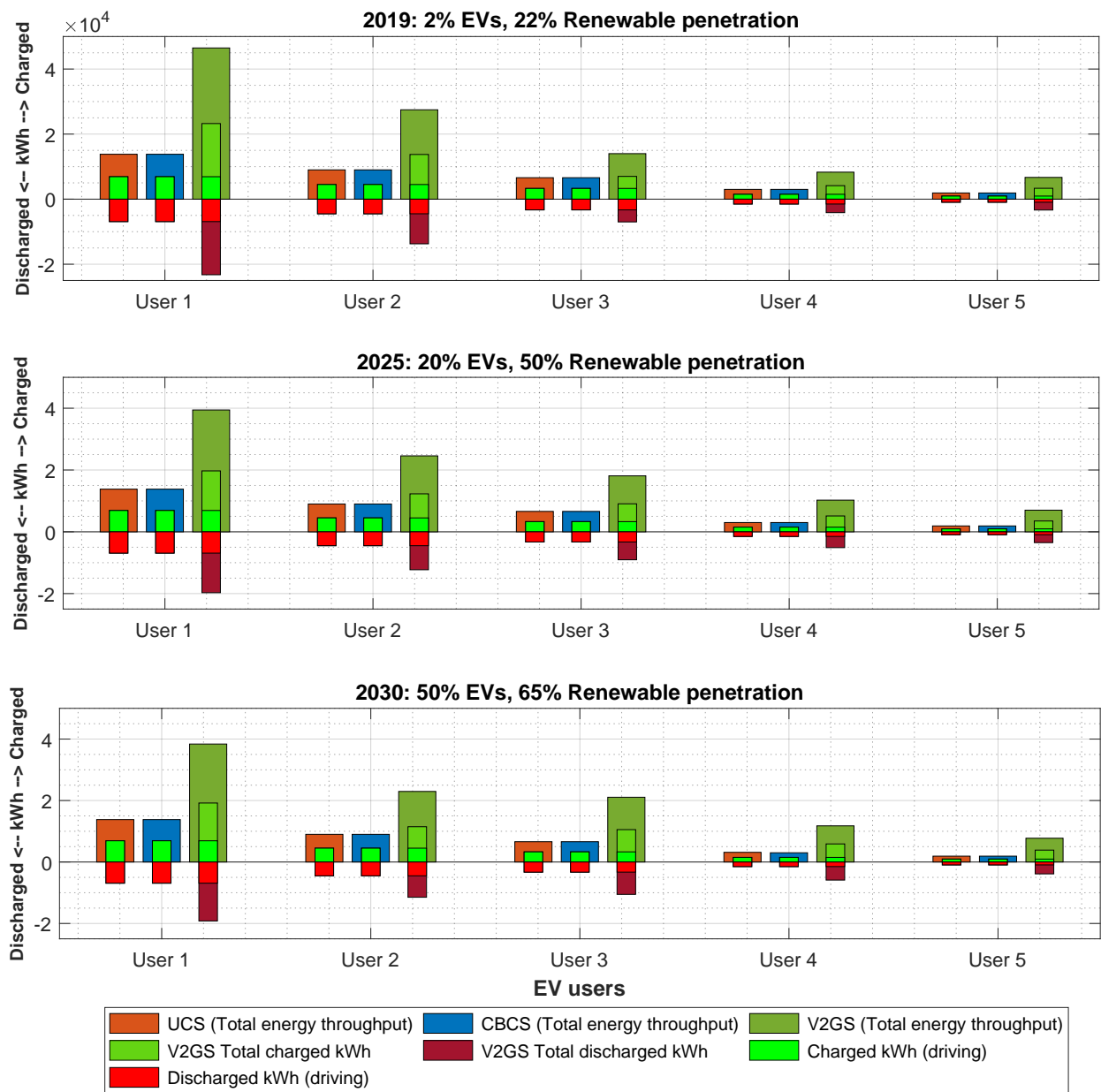

FiguRE 4.4: Total battery energy throughput, charged kWh and discharged $\mathrm{kWh}$ of EVs under UCS (baseline scenario), CBCS and V2GS

Battery energy throughput is very important parameter to measure during the study of V2G. As V2GS, involves charging and discharging of battery based on prices, energy throughput of battery is increased significantly. With higher battery energy throughput, battery degrade faster than usual. Although, degradation of the battery is very complex phenomena and have been discussed already in the section of theoretical background, energy throughput model simplify the degradation calculation and relate it directly with the energy throughput.

In the figure 4.4 , total battery energy throughput due to mentioned charging strategies are compared. Moreover, it also includes charged $\mathrm{kWh}$ and discharged $\mathrm{kWh}$ due to driving purpose (baseline) and V2GS. Charged kWh due to driving purpose, represent the charging need of an EV in baseline scenario. Energy throughput under UCS and CBCS should be the same as both have only uni-directional charging capabilities and do not demand the charge further than the EVs driving demand.

In the same figure, it can be seen that User 1 has a highest battery energy throughput, charged $\mathrm{kWh}$ and discharge $\mathrm{kWh}$ due to driving and V2GS. Which is because user's highest driving usage and availability of charge-point at both home and workplace location. Availability of charge-points at both home and workplace 
location increases it's plug-in duration. In the same way, User 4 has the least battery energy throughput, charged $\mathrm{kWh}$ and discharged $\mathrm{kWh}$ due to driving and V2GS because of it's low daily driving usage as well as low plug-in-duration.

In the case of V2GS, battery energy throughput is increased in between 2-3 times more than the baseline (or other) charging strategies in 2019. It can be easily observed that bigger the size of battery, higher the difference between the baseline energy throughput and V2GS energy throughput. It is also observed that for some users total energy throughput is decreased or increased over the years.

For example, energy throughput of User 3's EV is increased steadily over the years. As the user is charging at workplace location in a day-time, with increase in solar capacities in renewable share over the years, prices during this period becomes cheaper and volatile as we seen in the previous section. More volatile prices increase the competition for EV users for the engagement in the market. So EVs are charging and discharging more than before, which increases their battery energy throughput. Phenomena of decrease in battery energy throughput over the years can be explained in the reverse way.

\subsubsection{Charging Costs and V2G Benefit}

In this section, annual charging costs for the different charging strategies have been compared for the selected EV users. As mentioned in the last chapter, spot market prices or energy prices are very small percentage of real electricity price or charging prices of an EV. EV Charging costs are calculated with the described method in the last chapter. This prices have been also compared with the real charging prices in the Netherlands provided by the different charging operators and service providers. Average prices for EV charging are lying around $€ 0.30$ per $\mathrm{kWh}$ in the Netherlands, where as in this study average charging prices calculated are around $€ 0.25$ per kWh. However, in this study fixed charge costs and subscription costs have not been considered because of high variation in the prices per charge session implied by different service providers [40].

In figure 4.6, it can be observed that in all scenarios charging costs are very high compared to V2G benefit. It is because, taxes and supplier's costs are calculated and added per kWh energy consumption for driving usage and independent of energy price variation. So these prices are similar for all the charging strategies for different users.

Comparing the charging costs and benefits of different EV users, similar trend has been found as battery energy throughput. Charging costs and benefits are highest for the user 1 which is expected because of highest daily driving distance, larger battery capacity and highest plug-in duration. Similarly lowest charging cost and negligible benefit is achieved by the user 5 who has the smallest battery capacity, driving usage and plug-in duration.

Compared to other users, charging costs and benefits of user 3 is increasing over the years. It is because user 3 is charging at workplace, and over the year with the rise of solar capacities in the energy mix, decreases the market prices drastically. So user 3 can charge at lower prices during the noon time and provide it back during the peak of the prices at higher prices. In that way user 3 decrease the overall charging costs under the V2GS. 

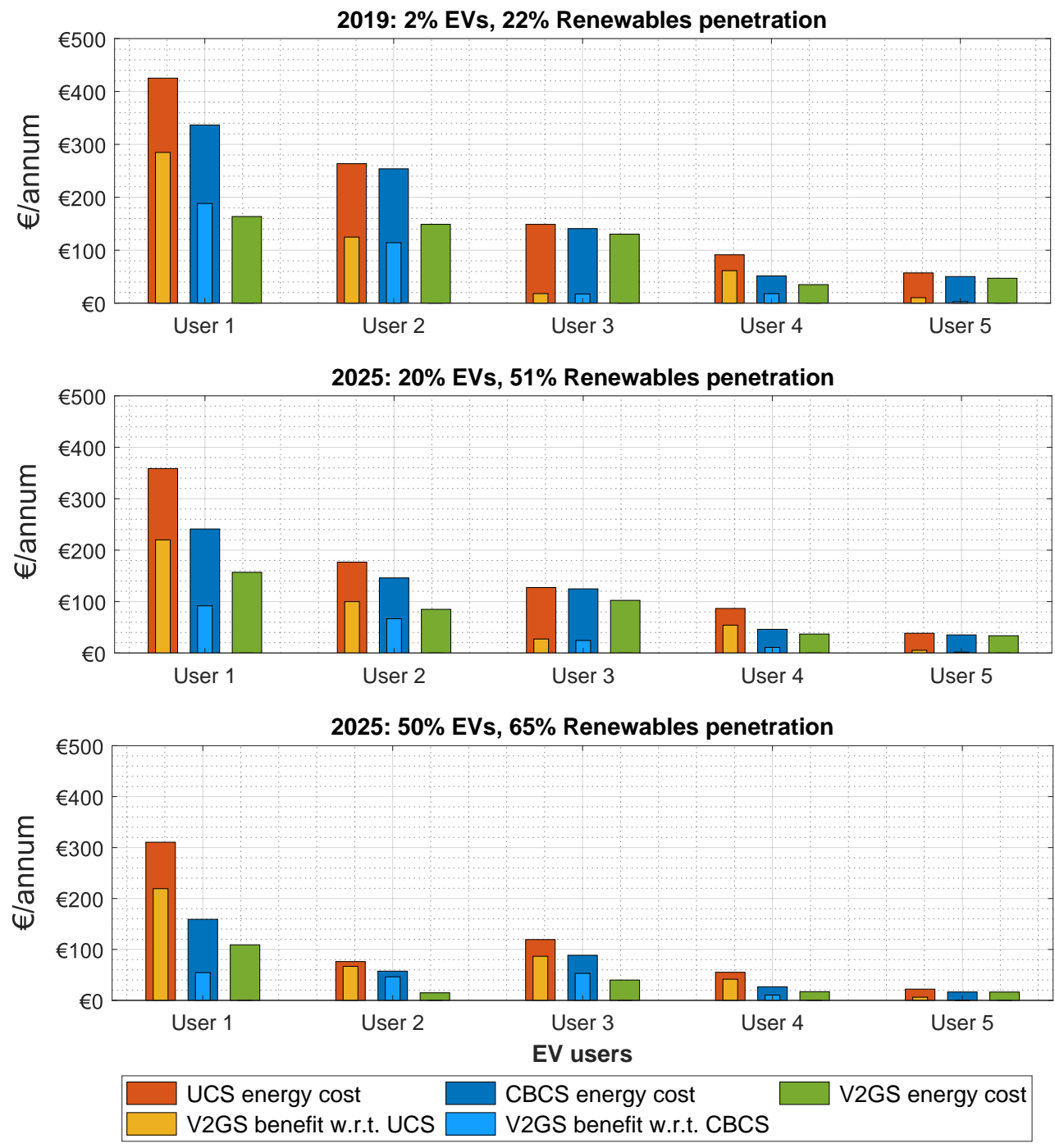

FIGURE 4.5: Comparison of energy costs based on different charging strategies and V2GS benefit w.r.t. UCS and CBCS

In the figure 4.6, it is visualised that charging costs are decreasing over the years for all the charging strategies and users. It is because of decrease in average spot market prices over the years as renewable penetration in to the energy system increase. To observe this effect more clearly, it is advised to check the energy cost chart included in the figure 4.5. It represents energy costs for different EV users under mentioned charging strategies.

It can be observed that UCS charging cost is always higher than any other charging strategy cost, followed by smart charging cost for all the users. It can also be seen that different EV users have different charging cost which is expected as they have unique attributes in terms of driving pattern, electric vehicle battery capacity, charging location, charge-point power and plug-in duration.

One exception is that, despite having larger battery capacity and plug-in duration, user 3 is gaining less benefit than user 4, for which one reason can be user 3's higher usage of an EV comparatively user 4, because of work trips and charging at the work location. While User 4 is making very short day trips and doing V2G 

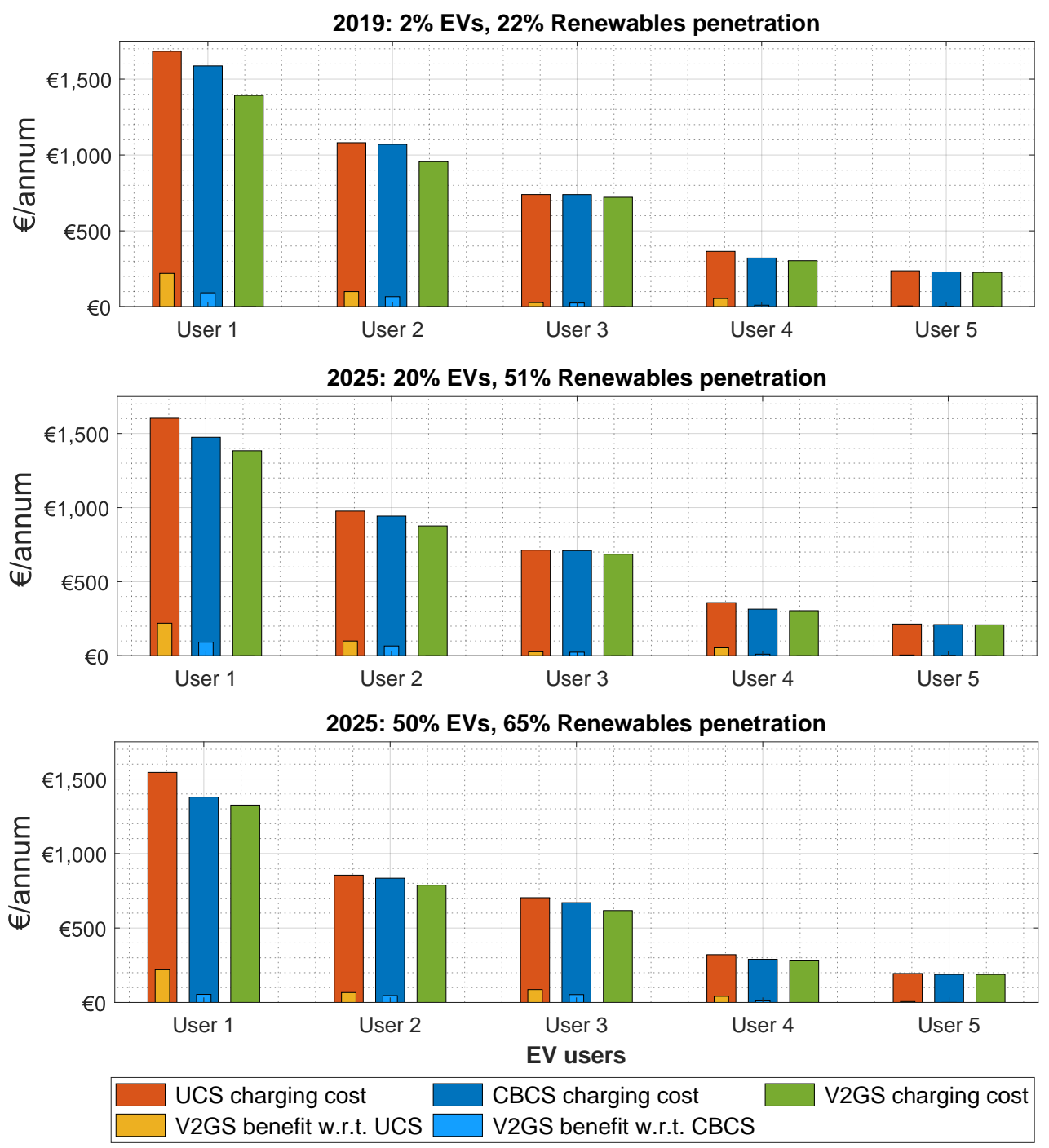

Figure 4.6: Comparison of charging costs based on different charging strategies and V2GS benefit w.r.t. UCS and CBCS

overnight at public charge-point every second day.

In this section $\mathrm{V} 2 \mathrm{G}$ benefits are calculated without the degradation costs included. In the next section net benefit of V2G will be calculated by integrating battery degradation costs.

\subsubsection{Battery Degradation Cost and V2G Net Benefit}

In this study cost of battery degradation has been calculated based upon the energy throughput model discussed in the the theoretical background. This study also takes into consideration the residual value of battery. It is important to consider because it provides the difference of value at the end of the life in the case of V2G or without V2G. For example, if we compare the scenario of the user doing V2G and not doing $\mathrm{V} 2 \mathrm{G}$, there will be huge difference in residual value of the battery at the end of the vehicle's life. Because V2Gs has already used more cycles or capacity than the scenario of without $\mathrm{V} 2 \mathrm{G}$, which makes them less valuable. 
For the calculation of the battery degradation costs, energy throughput, depth of discharge (DoD) and C-rate has been taken into consideration. As it is discussed in the theory part of the battery degradation, higher C-rate has non-linear influence on battery degradation, it is vital to analyse the C-rate during the V2G scenarios as well as other charging strategies. However during the study, it is found out that the maximum EV charging power taken in to consideration $(22 \mathrm{~kW})$ is less than the lowest battery capacity $(30 \mathrm{kWh})$ considered for the study. It means C-rate is always lesser than $1 \mathrm{C}$ and as discussed in before influence of it can be ignored.

During the simulation, DoD is calculated based upon V2GS scheduling of EV charging. As simulations run over the year and research is analysing the yearly charging and degradation costs, average DoD of the battery is found to be suitable for the calculation of degradation costs.

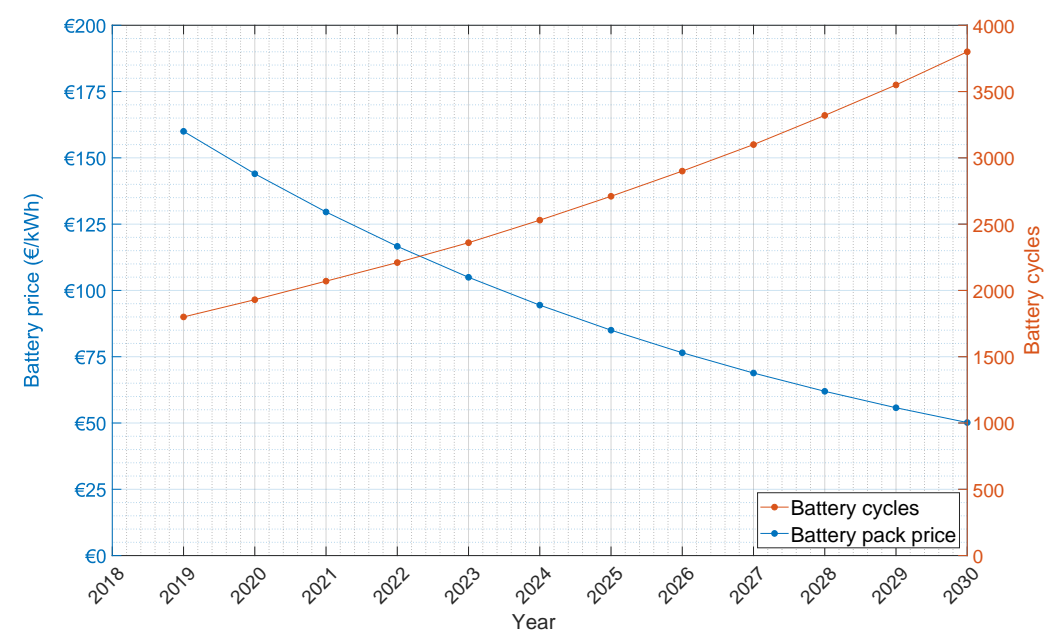

Figure 4.7: Projected Battery prices and Battery cycles $(100 \%$ DoD)

Battery prices and battery cycles are important terms to consider in the calculation of battery degradation cost. As these terms have direct influence on the battery degradation costs, variation in them should be take into consideration over the years.

During the calculation of battery degradation, it has been assumed that the cost of degradation is zero if battery cycles or total energy throughput due to driving plus V2G outlasts the vehicle's lifetime (18.3). For the cost calculation of battery degradation,annual gross average $\mathrm{V} 2 \mathrm{G}$ benefit of the three scenarios have been taken into consideration and multiplied it with the vehicle's lifetime to get the V2G lifetime benefit.

Figure 4.7 has been plotted from the battery prices projected by the BNEF[3]. They have considered $18 \%$ learning rate from the observed historical values of the battery prices. These prices should be considered as average expected prices. Battery cycle life is varying significantly from one type of battery cells to another. In the current year it is also found that there are some battery chemistry already are claiming more than 5000 cycle life under $100 \%$ DoD and standard temperature range. However, in this study pessimistic assumptions have been made for the battery cycle life predictions which can be noticed in the figure 4.7 . 

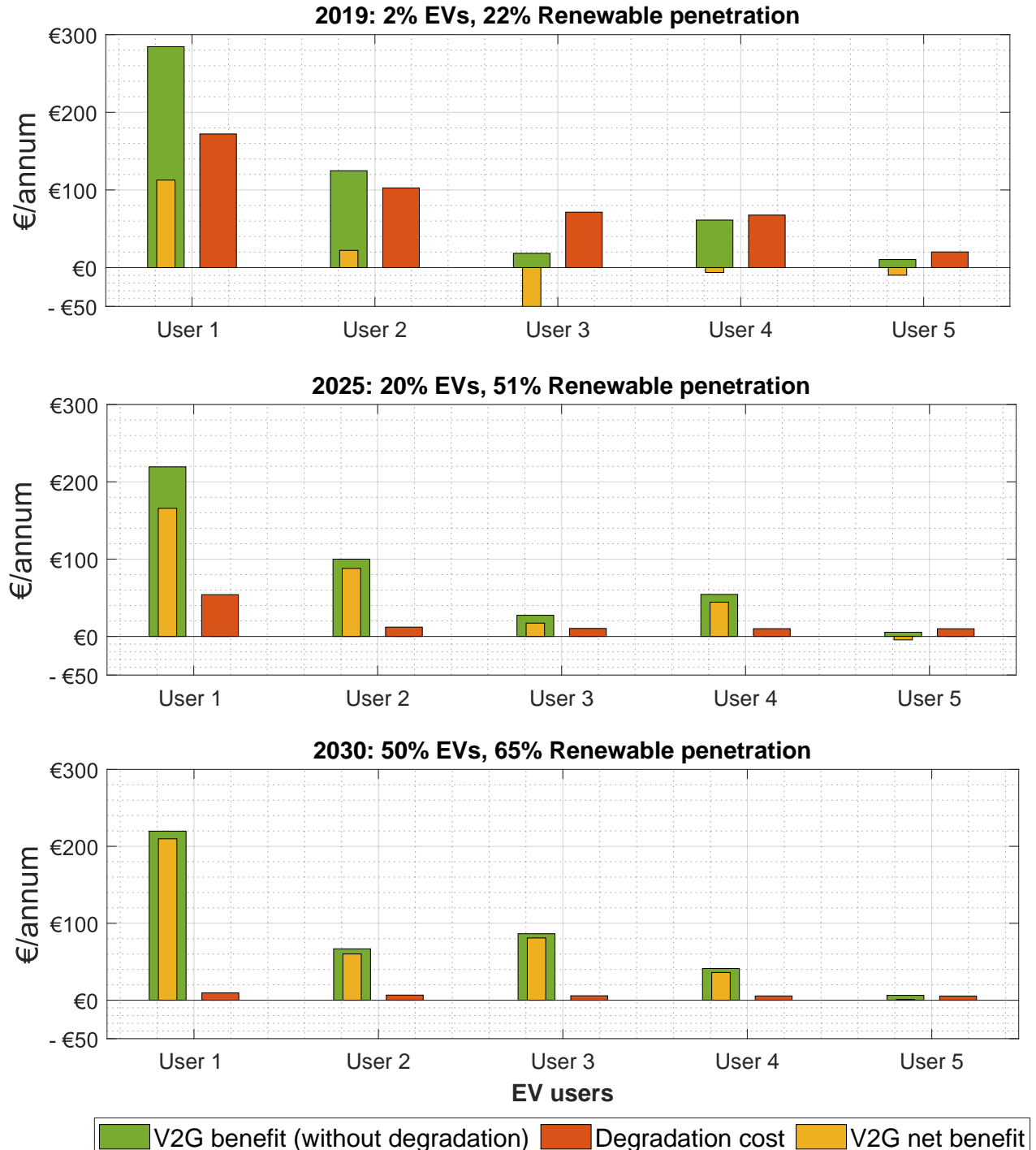

FigURE 4.8: V2G net benefit and degradation costs

In the figure $4.8 \mathrm{~V} 2 \mathrm{G}$ net benefit and battery degradation cost are presented for the different users and scenarios. V2G net benefit is calculated by subtracting the degradation costs from the $\mathrm{V} 2 \mathrm{G}$ benefit previously calculated with respect to other charging strategies.

It is clearly observed in the figure 4.8 that the battery degradation costs are decreasing drastically over the years. The foremost reasons for that is the decrease in the battery prices and increase in battery cycle life over the years. It can be visualised in 2025 scenario that user 2,3,4 and has very small difference in gross benefit and net benefit of V2G. It is because of all this user's battery cycle life is exceeding total lifetime cycles or energy throughput due to driving and V2G. It makes the battery degradation cost zero and only residual value difference remains in the cost.

In 2030 scenario, all the user's battery degradation costs are becoming negligible as it can be noticed in the figure. From these results, it can be conclude that price of battery and cycle life are key factors in determining the V2G benefits. With 
the decrease in battery prices and increase in battery cycle life over the years, degradation costs are becoming negligible and $\mathrm{V} 2 \mathrm{G}$ is becoming more profitable than current year prices.

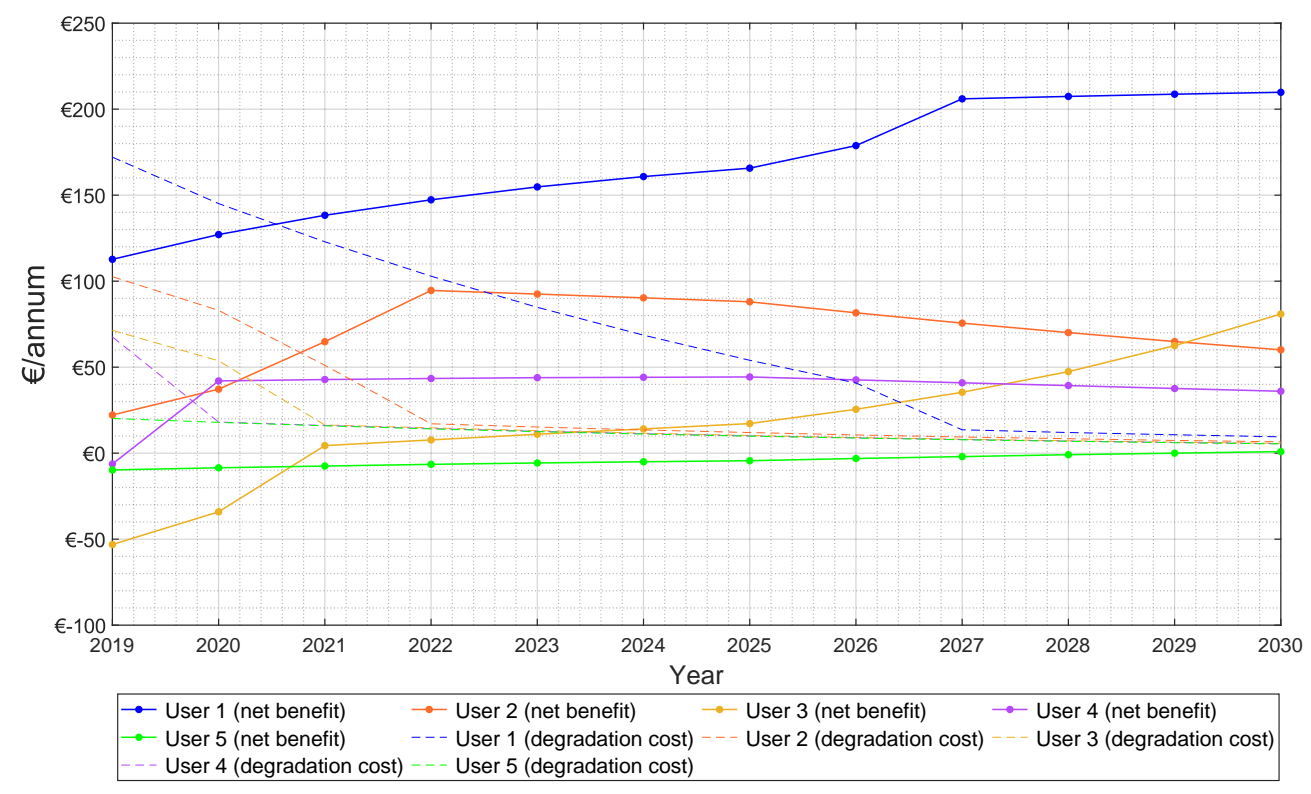

Figure 4.9: V2G net benefit and degradation costs: 2019-2030

\subsection{Sensitivity Analysis}

\section{EV charging power sensitivity analysis}

Sensitivity analysis of V2G benefit for varying charging power carried out with respect to other charging strategies (UCS, CBCS). It can be seen in the figure 4.10 that with increasing the charging power, benefits are increasing for all the EV users. However, increment in benefits are not the same for all the EV users. It increase in varying proportion for different EV users, mainly affected by the capacity of the battery.

Comparison of V2G benefits with UCS and CBCS, it can be found from both the figure 4.10, 4.11 that V2GS benefits are decreased with respect to CBCS compared to UCS, which is expected because of CBCS cost effective uni directional charging strategy execution. However, with the lower charging power V2G charging costs are equalising the cost of CBCS charging. One explanation for that is that profitability of energy arbitrage lies in how much energy battery can discharge when there is highest prices and how much it can charge during the lowest prices. The more it can charge or discharge, the more benefit it can get. 


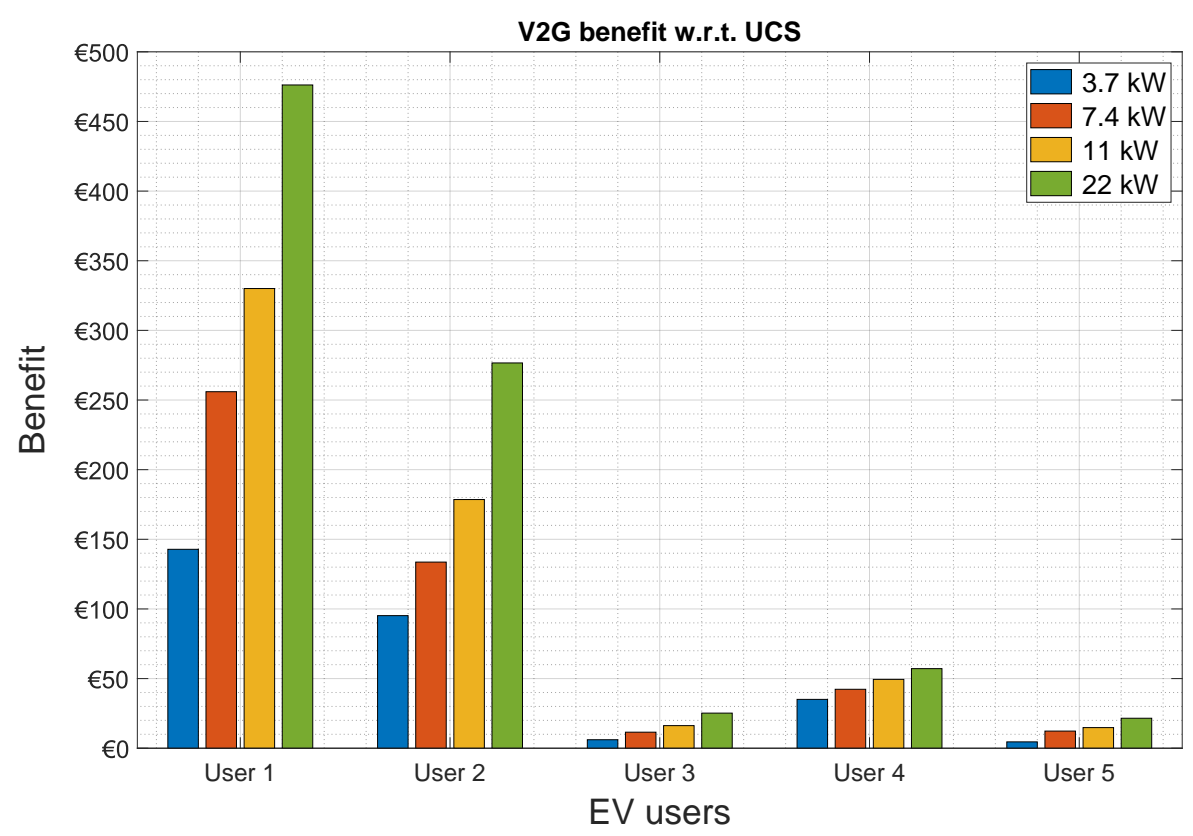

FIGURE 4.10: V2G benefit w.r.t. UCS with varying charging power

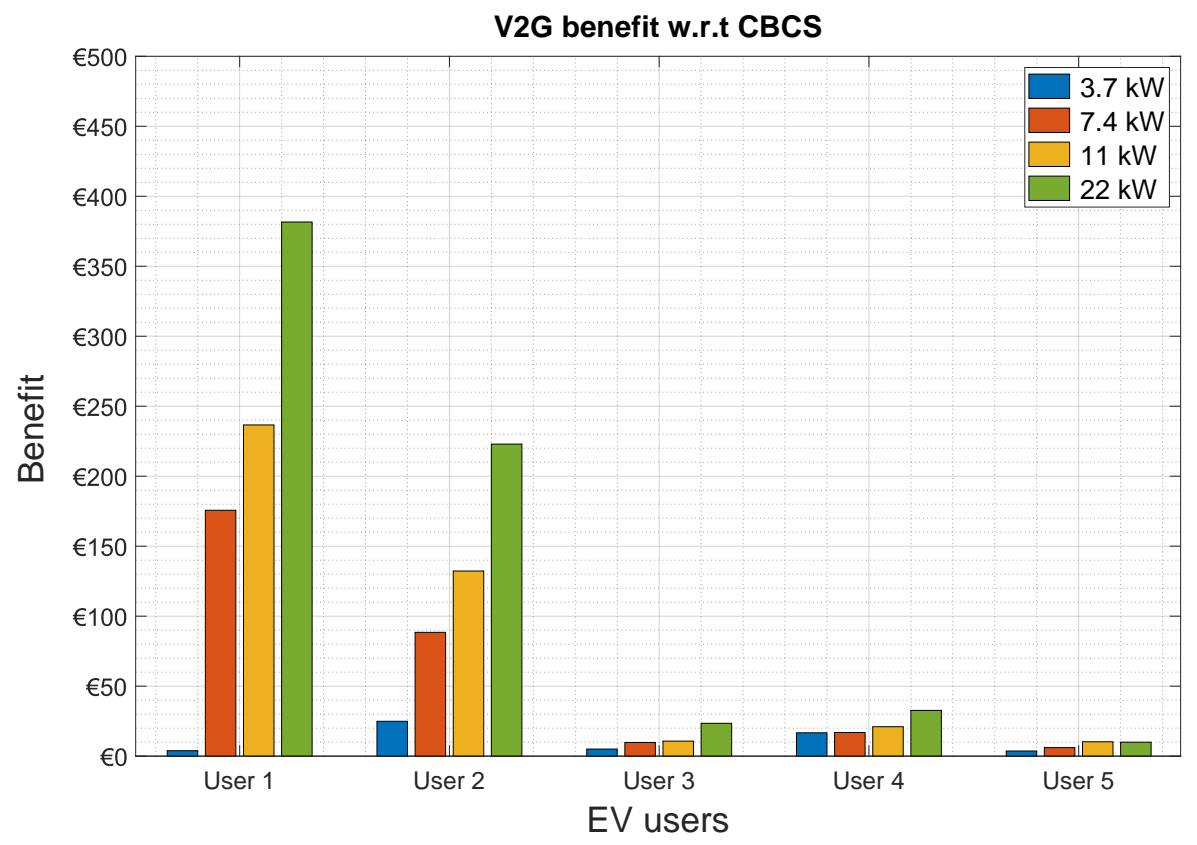

FiguRe 4.11: V2G benefit w.r.t. CBCS with varying charging power 


\section{Chapter 5}

\section{Conclusion}

In this study V2G monetary benefits are researched for the EV users in the Netherlands. Study specifically focus on EV users trading at spot market in the Netherlands while providing V2G storage (arbitrage). Moreover, battery lifetime economic analysis have also taken into consideration for the calculation of V2G net benefits. Formulated research question has been studied in a agent-based model approach which comprises the different behaviours \& characteristics of actors (EV users), their collective influence on spot market and in turn their individual V2G benefit which is affected by the global change in prices of spot market.

\subsection{Influence of V2GS on Energy System}

Influence of V2GS on electricity market is positive compared to other two strategies. It can provide high amount of flexibility that is needed in the time of peak or valley demand. In the future, volatility in market prices will be increased because of high renewable penetration rate and EV adoption. V2G is decreasing this volatility significantly. In 2019, RMSE for the UCS is $6.98 € / \mathrm{MWh}, \mathrm{CBCS}$ is $6.76 € / \mathrm{MWh}$ and for V2GS it is $6.40 € /$ MWh. In 2030, In high volatile market, RMSE for the UCS is $16.71 € / M W h$, for CBCS it it $14.21 € /$ MWh and $13.12 € /$ MWh for V2GS It shows $\mathrm{V} 2 \mathrm{G}$ can be taken as a good option for the future flexibility market when more renewable are adopted.

In the neighbourhood, $60 \% \mathrm{EV}$ users are working and out of which $30 \%$ are charging their EV at workplace charge points. Results shows that with the increasing amount of PV in the renewable mix, prices will decrease significantly in the day time. If there are more work EV chargers available, surplus amount of solar production can be stored in to the batteries of these vehicle during the day and can be feedback during the peaks in the evening. There is huge potential of solar charging in the day time with the increasing amount of PV installation which can be seen in the figure 4.2 .

On local electricity network, V2G can decrease the peak demand and provide the energy locally to users in peak time. However, with the high penetration of EV, it increased the overall load significantly compared to other two strategies. It is because of high energy flow rate due to bi-directional charging. Local grid operator can research in-depth about this effect of V2G on their network, as V2G also provide value to the grid operator. 


\subsection{Monetary Benefits of EV Users}

Influence on monetary benefits of EV users are studied at two different levels: System level (spot market prices, EV adoption and renewable penetration) and Individual level (battery capacity size, charging power, driving pattern).

Change in the system over the year 2019,2025 and 2030 brings different results for different EV users. It has been found that for some users benefits are decreasing or becoming stagnant over the years, for some it is increasing. It has strong correlation with the user's charging location and time. As high arbitrage benefits depends on volatility of the prices, with high EV adoption this volatility is decreased and benefits of its are distributed in between the larger group of EV users (with high adoption). Which in turn decrease the individual benefits. Such phenomenon is occurring during night time in 2025 and 2030 where there are large numbers of EV users providing $\mathrm{V} 2 \mathrm{G}$ with lesser need of flexibility in the system. That is the reason of decreasing benefits of EV users who are charging at night.

On the other hand, user providing V2G in day-time has less flexibility demand to provide to system during the day in 2019, while it is increasing with more PV installation in the system. Therefore, user's benefits are also increasing.

It has been found that influence of individual characteristics on monetary benefits are very high. Battery capacity size is strongly correlated to the benefits of V2G. However, charging location or time of charging is also playing the role in the benefits. In general, V2G benefits are higher for the user having larger battery capacity and with longer plug-in duration and vice versa. If we compare the annual benefits of EV users, with their baseline charging costs, it is actually very low compare to other markets (RRP) in the Netherlands. If we compare the benefits of spot market trading with RRP market, RRP market benefits ranges from $€-14,60$ to $€ 773,80$ for smallest battery capacity to largest battery capacity respectively [61].

Spot market trading includes higher taxes and tariffs which are fixed on per $\mathrm{kWh}$ consumption and these costs are same for the all the EV charging strategies. These taxes could be even higher in the case of V2G if we consider the round-trip efficiency. Moreover, EV users are connected to charge point for very longer period of time to gain low benefits. It also increase the usage time of the charge-point for the low benefits gain.

\subsection{Battery Degradation Costs and Lifetime Economic Analysis}

Battery degradation costs and residual value of the battery has huge impact on net benefits of V2G. Cost of battery degradation is very high due to higher energy flow during the V2G operation. Energy throughput due to V2G is almost 3 times bigger than than the baseline scenario. With decreasing prices of the battery over the year, battery degradation costs are decreasing and net benefits are increasing for the EV users. However, the calculation of the degradation costs have been calculated in simple manner which only takes into consideration total energy throughput (or equivalent full cycles), DoD and charge-discharge rate. 
It has been found during the research that, as battery total energy throughput (or equivalent full cycles) outlasts the cycles used for driving purpose and V2G arbitrage, battery degradation costs will be zero and there is only residual value difference remained as cost for $\mathrm{V} 2 \mathrm{G}$. 


\section{Chapter 6}

\section{Discussion}

In this chapter several of the limitations that have been imposed for the study are discussed. These limitations are mostly required to narrow down the scope of the research. This chapter present the limitations and their possible impact on the results of the research. In the second section future work will be present that can possibly extend the topic or improve the gaps exists in the current study.

\subsection{Limitations}

In this study, it has been assumed for the simplification of modelling that EV can be able to trade at spot market by eliminating the mediator party such as aggregator. However, in the real life scenario it can only takes place with aggregator because of bidding size capabilities and advantage of large pooling. Approach similar to the study has been found in the literature where trading of electricity is done in two stage, where in first stage,electricity is traded on day-ahead market based on historical driving and charging pattern [37]. In the second stage, deviations from the prediction can be adjusted on intra-day market. Same can be assumed for the aggregator's portfolio where EV access to prices reflecting spot market prices and optimise their schedule based on these price. Deviation into the charging pattern or time of leaving can be adjusted by the aggregator on intra-day market. However, in this study only day-ahead prices are taken into consideration because of already modelled spot market.

In the current study, spot market has been modelled with fitting method, for the validation of this method APX prices and average hourly demand curves from the different years should be used. However, due to lack of availability of data of APX prices for the other years it has not been possible to validate it with current year or last year prices. So 2016 APX prices have been used for the validation of the spot market prices. Moreover, spot market are unable to forecast the prices correctly for long term such as 2030, it is because in the next decade market will be changed drastically and flexibility providers will be added to the energy market such as batteries and prices for renewable curtailment. For which how market will be designed is unknown.

It is assumed that charging-discharging of an EV is done with $100 \%$ round-trip efficiency as it is not cleared completely how much energy loss is occurring during the operation of V2G. Moreover, it follows the steps of V2G community of researchers $[63,13,18]$. However, recently research has been done on the round-trip efficiency of $\mathrm{V} 2 \mathrm{G}$ services and it has found that round-trip efficiency offset more than half of 
the revenue from the V2G frequency regulation in PJM market. It can make huge impact on the profitability of the $\mathrm{V} 2 \mathrm{G}$ services.

In the current study, battery degradation has been studied with simple approach due to constraints of time. However, literature review for battery degradation has been done thoroughly. During the research it has also been found that battery degradation is very complex phenomenon to understand and better empirical models are needed to validate the real cost of battery degradation.

\subsection{Future Work}

- This study examines the different charging strategies separately in respective years, however it would be interesting to assess the scenarios where varying percentage of agent population are executing different charging strategies in the neighbourhood.

- Current profit maximisation algorithm doesn't take into account the battery degradation cost while executing V2GS, further research into developing algorithm considering battery degradation cost is recommended. In addition, V2G algorithm/strategy developed by [56] should be considered, which claim of improving the battery life with their V2G algorithm compared to baseline scenario.

- Consumer acceptance for V2G should be researched into detailed and based on this research, behaviour of agents can be modelled in the context of V2G in SparkCity model.

- Cost of battery degradation plays a vital role in V2G services. Further research is recommended into the calculation of battery degradation with updated battery models, battery chemistry and cycle life. Energy-throughput models can be strengthen further with the empirical validation of it. 


\section{Bibliography}

[1] AnyLogic Wikipedia. May 2019. URL: https://en.wikipedia.org/w/index. php?title=AnyLogic\&oldid=898532085.

[2] URL: https://www.nedu.nl/documenten/verbruiksprofielen/.

[3] A Behind the Scenes Take on Lithium-Ion Battery Prices. Mar. 5, 2019. URL: https://about. bnef . com/blog/behind-scenes-take-lithium-ionbattery-prices/ (visited on 05/09/2019).

[4] A Bit About Batteries. Nov. 30, 2006. URL: https://www.tesla.com/blog/ bit-about-batteries (visited on 06/09/2019).

[5] "A Conceptual Framework for the Vehicle-to-Grid (V2G) Implementation". In: ().

[6] A. T. Al-Awami and E. Sortomme. "Coordinating Vehicle-to-Grid Services With Energy Trading". In: IEEE Transactions on Smart Grid 3.1 (Mar. 2012), pp. 453-462. ISSN: 1949-3053. DOI: 10.1109/TSG.2011.2167992.

[7] R. J. Bessa and M. A. Matos. "The Role of an Aggregator Agent for EV in the Electricity Market". In: 7th Mediterranean Conference and Exhibition on Power Generation, Transmission, Distribution and Energy Conversion (MedPower 2010). 7th Mediterranean Conference and Exhibition on Power Generation, Transmission, Distribution and Energy Conversion (MedPower 2010). Nov. 2010, pp. 1-9. DOI: 10.1049/cp. 2010.0866.

[8] Ricardo J. Bessa, Manuel A. Matos, filipe Joel Soares, and João A. Peças Lopes. "Optimized Bidding of a EV Aggregation Agent in the Electricity Market". In: IEEE Trans. Smart Grid 3.1 (Mar. 2012), pp. 443-452. ISSN: 1949-3053, 1949-3061. DOI: 10 . 1109/TSG . 2011 . 2159632. URL: http: / / ieeexplore.ieee.org/document/6003808/ (visited on 05/24/2019).

[9] Andrei Borshchev. "Multi-method modelling: AnyLogic". In: DiscreteâEvent Simulation and System Dynamics for Management Decision Making. John Wiley \& Sons, Ltd, 2014. Chap. 12, pp. 248-279. ISBN: 9781118762745. DOI: 10. 1002/9781118762745 . ch12. eprint: https : //onlinelibrary . wiley . com/ doi / pdf / 10 . 1002/9781118762745 . ch12. URL: https : / / onlinelibrary . wiley.com/doi/abs/10.1002/9781118762745.ch12.

[10] Alec N Brooks. Report: 2002-12-10 Vehicle to Grid Demonstration Project: Grid Regulation Ancillary Service with a Battery Electric Vehicle, p. 61.

[11] M. Broussely, Ph. Biensan, F. Bonhomme, Ph. Blanchard, S. Herreyre, K. Nechev, and R. J. Staniewicz. "Main Aging Mechanisms in Li Ion Batteries". In: Journal of Power Sources. Selected Papers Pressented at the 12th International Meeting on Lithium Batteries 146.1 (Aug. 26, 2005), pp. 9096. ISSN: 0378-7753. DOI: 10.1016/j . jpowsour. 2005.03.172. URL: http: // www . sciencedirect.com/science/article/pii/S0378775305005082 (visited on 08/26/2018).

[12] Benergy BV. De opbouw van de energierekening - Energiewereld.nl. URL: https : / / www . energiewereld . nl / energienota / de - opbouw - van - de energierekening. 
[13] Andrew De Los Rios, Jarrod Goentzel, Kristen E Nordstrom, and Clay W Siegert. "Economic analysis of vehicle-to-grid (V2G)-enabled fleets participating in the regulation service market". In: 2012 IEEE PES Innovative Smart Grid Technologies (ISGT). IEEE. 2012, pp. 1-8.

[14] Jacques Després, Silvana Mima, Alban Kitous, Patrick Criqui, Nouredine Hadjsaid, and Isabelle Noirot. "Storage as a flexibility option in power systems with high shares of variable renewable energy sources: a POLES-based analysis". en. In: Energy Economics 64 (May 2017), pp. 638-650. ISSN: 01409883. DOI: $10.1016 / j$.eneco.2016.03.006. URL: https://linkinghub.elsevier. com/retrieve/pii/S0140988316300445 (visited on 11/29/2018).

[15] Electrification Is Key to an Energy Transition in Transport. Feb. 10, 2019. URL: https : / / www . agora-verkehrswende .de/en/12-insights / electrification - is - key - to - an-energy - transition-in-transport / , \% 20https : / / www . agora - verkehrswende . de / en / 12 - insights / electrification - is - key - to - an - energy - transition - in - transport/ (visited on 05/08/2019).

[16] Sheridan Few, Oliver Schmidt, Gregory J. Offer, Nigel Brandon, Jenny Nelson, and Ajay Gambhir. "Prospective Improvements in Cost and Cycle Life of OffGrid Lithium-Ion Battery Packs: An Analysis Informed by Expert Elicitations". In: Energy Policy 114 (Mar. 1, 2018), pp. 578-590. ISSN: 0301-4215. DOI: 10.1016/j . enpol . 2017.12.033. URL: http://www . sciencedirect. com/ science/article/pii/S0301421517308595 (visited on 05/31/2019).

[17] GROWTH WITHIN: A CIRCULAR ECONOMY VISION FOR A COMPETITIVE EUROPE.

[18] Sekyung Han and Soohee Han. "Economic Feasibility of V2G Frequency Regulation in Consideration of Battery Wear". In: Energies 6.2 (Feb. 6, 2013), pp. 748-765. ISSN: 1996-1073. DOI: 10.3390/en6020748. URL: http: //www .mdpi . com/1996-1073/6/2/748 (visited on 04/13/2019).

[19] Auke Hoekstra and Peter Hogeveen. "Agent-Based Model for the Adoption and Impact of Electric Vehicles in Real Neighbourhoods". In: (), p. 17.

[20] Anderson Hoke, Alexander Brissette, Dragan Maksimovic, Annabelle Pratt, and Kandler Smith. "Electric Vehicle Charge Optimization Including Effects of Lithium-Ion Battery Degradation". In: 2011 IEEE Vehicle Power and Propulsion Conference. 2011 IEEE Vehicle Power and Propulsion Conference (VPPC). Chicago, IL, USA: IEEE, Sept. 2011, pp. 1-8. ISBN: 978-1-61284248-6. DOI: 10.1109/VPPC.2011.6043046. URL: http://ieeexplore.ieee. org/document/6043046/ (visited on 09/26/2018).

[21] Tim Hoogvliet. "Assessing the Monetary Value and Impacts of Regulatingand Reserve Power Provision by Electric Vehicles in Dutch Urban Areas".

[22] Nina Juul, Giovanni Pantuso, Jan Emil Banning Iversen, and Trine Krogh Boomsma. "Strategies for Charging Electric Vehicles in the Electricity Market". In: International Journal of Sustainable Energy Planning and Management (Nov. 20, 2015), 67-74 Pages. DOI: 10.5278/ijsepm.2015.7.6. URL: https: // journals . aau.dk/index.php/sepm/article/view/1017 (visited on $02 / 21 / 2019)$.

[23] Willett Kempton and Steven E. Letendre. "Electric Vehicles as a New Power Source for Electric Utilities". In: Transportation Research Part D: Transport and Environment 2.3 (Sept. 1997), pp. 157-175. ISSN: 13619209. DOI: 10. 1016/S1361-9209(97)00001-1. URL: https://linkinghub.elsevier.com/ retrieve/pii/S1361920997000011 (visited on 03/19/2019). 
[24] Willett Kempton and Jasna Tomić. "Vehicle-to-Grid Power Fundamentals: Calculating Capacity and Net Revenue". In: Journal of Power Sources 144.1 (June 2005), pp. 268-279. ISSN: 03787753. DOI: 10 . 1016/j . jpowsour . 2004.12.025. URL: https://linkinghub.elsevier.com/retrieve/pii/ S0378775305000352 (visited on 02/09/2019).

[25] Willett Kempton and Jasna Tomić. "Vehicle-to-Grid Power Implementation: From Stabilizing the Grid to Supporting Large-Scale Renewable Energy". In: Journal of Power Sources 144.1 (June 2005), pp. 280-294. ISSN: 03787753. DOI: 10.1016/j . jpowsour. 2004 .12.022. URL: https://linkinghub.elsevier. com/retrieve/pii/S0378775305000212.

[26] Franziska Klügl. "A Validation Methodology for Agent-based Simulations". In: Proceedings of the 2008 ACM Symposium on Applied Computing. SAC '08. Fortaleza, Ceara, Brazil: ACM, 2008, pp. 39-43. ISBN: 978-1-59593-753-7. DOI: 10.1145/1363686.1363696. URL: http://doi.acm.org/10.1145/1363686. 1363696.

[27] D. Li. "Aging Mechanisms of Li-Ion Batteries : Seen from an Experimental and Simulation Point of View". PhD thesis.

[28] Henrik Lund and Willett Kempton. "Integration of Renewable Energy into the Transport and Electricity Sectors through V2G". In: Energy Policy 36.9 (Sept. 1, 2008), pp. 3578-3587. ISSN: 0301-4215. DOI: 10.1016/j .enpol. 2008. 06.007. URL: http://www. sciencedirect.com/science/article/pii/ S0301421508002838 (visited on 04/22/2019).

[29] B. Lunz, H. Walz, and D. U. Sauer. "Optimizing Vehicle-to-Grid Charging Strategies Using Genetic Algorithms under the Consideration of Battery Aging". In: 2011 IEEE Vehicle Power and Propulsion Conference. 2011 IEEE Vehicle Power and Propulsion Conference. Sept. 2011, pp. 1-7. DOI: 10.1109/ VPPC. 2011.6043021

[30] C. M. Macal and M. J. North. "Tutorial on agent-based modeling and simulation". In: Agent-Based Modeling and Simulation. Ed. by Simon J. E. Taylor. London: Palgrave Macmillan UK, 2014, pp. 11-31. ISBN: 978-1-137-453648. DOI: 10 . 1057 / 9781137453648 _2. URL: https : / / doi . org/10 . 1057 / 9781137453648_2.

[31] C M Macal and M J North. "Tutorial on agent-based modelling and simulation". In: Journal of Simulation 4.3 (Sept. 2010), pp. 151-162. ISSN: 1747-7786. DOI: 10.1057/jos.2010.3. URL: https://doi.org/10.1057/jos.2010.3.

[32] V. Marano, S. Onori, Y. Guezennec, G. Rizzoni, and N. Madella. "Lithium-Ion Batteries Life Estimation for Plug-in Hybrid Electric Vehicles". In: 2009 IEEE Vehicle Power and Propulsion Conference. 2009 IEEE Vehicle Power and Propulsion Conference (VPPC). Dearborn, MI: IEEE, Sept. 2009, pp. 536543. ISBN: 978-1-4244-2600-3. DOI: 10.1109/VPPC. 2009.5289803. URL: http: //ieeexplore. ieee.org/document/5289803/ (visited on 04/28/2019).

[33] Merit Order. In: Wikipedia. Page Version ID: 875417823. Dec. 26, 2018. URL: https : / / en . wikipedia.org/w/index . php?title=Merit_order\&oldid= 875417823 (visited on 05/05/2019).

[34] Michiel van Lelyveld. "Simulating Smart Charging in Dutch Neighbourhood". Utrecht: Utrecht University, Oct. 25, 2017.

[35] Mario J. Miranda and Paul L. Fackler. Applied Computational Economics and Finance. Cambridge, Mass: MIT Press, 2002. 510 pp. ISBN: 978-0-262-13420-0.

[36] Daniel Myall, Dima Ivanov, Walter Larason, Mark Nixon, and Henrik Moller. Accelerated Reported Battery Capacity Loss in $30 \mathrm{kWh}$ Variants of the Nissan Leaf. preprint. ENGINEERING, Mar. 15, 2018. DOI: 10 . 
20944 / preprints201803 . 0122 . v1. URL: http : / /www . preprints . org / manuscript/201803.0122/v1 (visited on 05/01/2019).

[37] Ilham Naharudinsyah and Steffen Limmer. "Optimal Charging of Electric Vehicles with Trading on the Intraday Electricity Market". In: Energies 11.6 (June 2018), p. 1416. DOI: 10.3390/en11061416. URL: https ://www .mdpi . com/1996-1073/11/6/1416 (visited on 12/10/2018).

[38] Muaz Niazi and Amir Hussain. "Agent-based computing from multi-agent systems to agent-based models: a visual survey". In: Scientometrics 89.2 (2011), p. 479.

[39] Lance Noel, Gerardo Zarazua de Rubens, Johannes Kester, and Benjamin K. Sovacool. Vehicle-to-Grid: A Sociotechnical Transition Beyond Electric Mobility. Cham: Springer International Publishing, 2019. ISBN: 978-3-03004863-1 978-3-030-04864-8. DOI: 10.1007/978-3-030-04864-8. URL: http:// link. springer.com/10.1007/978-3-030-04864-8 (visited on 04/13/2019).

[40] Overzicht-Laadtarieven.Pdf.

[41] Pbl-2017-Nationale-Energieverkenning-2017_2625.Pdf. URL: https://www . $\mathrm{pbl}$.nl/sites/default/files/cms/publicaties/pbl-2017-nationaleenergieverkenning-2017_2625.PDF (visited on 05/10/2019).

[42] Ahmad Pesaran, Kandler Smith, and Tony Markel. "Impact of the 3Cs of Batteries on PHEV Value Proposition: Cost, Calendar Life, and Cycle Life". en. In: (), p. 36.

[43] Scott B Peterson, Jay Apt, and JF Whitacre. "Lithium-ion battery cell degradation resulting from realistic vehicle and vehicle-to-grid utilization". In: Journal of Power Sources 195.8 (2010), pp. 2385-2392.

[44] Scott B. Peterson, J. F. Whitacre, and Jay Apt. "The Economics of Using Plug-in Hybrid Electric Vehicle Battery Packs for Grid Storage". In: Journal of Power Sources 195.8 (Apr. 15, 2010), pp. 2377-2384. ISSN: 0378-7753. DOI: 10. 1016/ j . jpowsour . 2009 .09 . 070. URL: http : / / www . sciencedirect . com/science/article/pii/S0378775309017303 (visited on 06/09/2019).

[45] P. Sánchez-Martín, S. Lumbreras, and A. Alberdi-Alén. "Stochastic Programming Applied to EV Charging Points for Energy and Reserve Service Markets". In: IEEE Transactions on Power Systems 31.1 (Jan. 2016), pp. 198-205. ISSN: 0885-8950. DOI: 10.1109/TPWRS. 2015. 2405755.

[46] Pekka Siika-aho. "Persona Creation Based on Secondary Data". In: (), p. 71.

[47] Benjamin K. Sovacool, Jonn Axsen, and Willett Kempton. "The Future Promise of Vehicle-to-Grid (V2G) Integration: A Sociotechnical Review and Research Agenda". In: Annual Review of Environment and Resources 42.1 (Oct. 17, 2017), pp. 377-406. ISSN: 1543-5938, 1545-2050. DOI: $10.1146 /$ annurev-environ-030117-020220. URL: http://www . annualreviews .org/ doi/10.1146/annurev-environ-030117-020220 (visited on 11/29/2018).

[48] Benjamin K Sovacool, Lance Noel, Jonn Axsen, and Willett Kempton. "The Neglected Social Dimensions to a Vehicle-to-Grid (V2G) Transition: A Critical and Systematic Review". In: Environmental Research Letters 13.1 (Jan. 1, 2018), p. 013001. ISSN: 1748-9326. DOI: 10.1088/1748-9326/aa9c6d. URL: http : / stacks . iop . org $/ 1748-9326 / 13 / i=1 / a=013001$ ? key=crossref . 9203e40373b5f1d7115356d673378c1b (visited on 11/29/2018).

[49] Centraal Bureau voor de Statistiek. Onderzoek Verplaatsingen in Nederland (OViN). URL: https : / / www . cbs . nl / nl - nl / onze - diensten / methoden / onderzoeksomschrijvingen / korte onderzoeksbeschrijvingen/onderzoek-verplaatsingen-in-nederland-ovin--. 
[50] Steinbuch. Tesla Model S Battery Degradation Data. Jan. 24, 2015. URL: https : / / steinbuch . wordpress . com / 2015 / 01 / 24 / tesla - model - s battery-degradation-data/ (visited on 08/20/2018).

[51] Summary for Policymakers of IPCC Special Report on Global Warming of $1.5^{\circ} \mathrm{C}$ Approved by Governments - IPCC. URL: https://www.ipcc.ch/ 2018 / 10 / 08 / summary - for - policymakers - of - ipcc - special - report on - global - warming - of - 1-5c-approved - by - governments/ (visited on 05/08/2019).

[52] Leigh Tesfatsion. "Introductory Notes on Agent-Based Modeling, AgentOriented Programming, \& AMES". In: (), p. 53.

[53] Tesla Battery Data Shows Path to over 500,000 Miles on a Single Pack - Electrek. URL: https : / / electrek . co/2016/11/01/tesla-battery degradation/ (visited on 05/05/2019).

[54] The Global Electric-Vehicle Market Is Amped up and on the Rise / McKinsey. URL: https : //www . mckinsey . com/industries/automotive-andassembly / our - insights / the - global - electric - vehicle - market - is amped-up-and-on-the-rise (visited on 05/09/2019).

[55] The Solid-Electrolyte Interphase. URL: https://www . youtube. com/watch? $\mathrm{v}=$ s0nuywN_et4 (visited on 11/14/2018).

[56] Kotub Uddin, Tim Jackson, Widanalage D. Widanage, Gael Chouchelamane, Paul A. Jennings, and James Marco. "On the Possibility of Extending the Lifetime of Lithium-Ion Batteries through Optimal V2G Facilitated by an Integrated Vehicle and Smart-Grid System". In: Energy 133 (Aug. 15, 2017), pp. 710-722. ISSN: 0360-5442. DOI: $10.1016 / j$. energy . 2017.04 . 116. URL: http : / / www . sciencedirect . com / science/article / pii / S0360544217306825 (visited on 08/20/2018).

[57] V2G Taxation in the Netherlands. In collab. with Auke Hoekstra.

[58] Koen H Van Dam, Igor Nikolic, and Zofia Lukszo. Agent-based modelling of socio-technical systems. Vol. 9. Springer Science \& Business Media, 2012.

[59] Marieke van Amstel. "Flexibility System Design for Electric Vehicles." In: (), p. 127.

[60] Marit van Hout, Paul Koutstaal, Ozge Ozdemir, and Ad Seebregts. "Quantifying Flexibility Markets". In: (), p. 52.

[61] Koen van Tilborgh. "Maximizing Prots for an Aggregator Providing Vehicleto-Grid and Smart Charging Services in the Dutch Market".

[62] Yuyang Wei and Martin Agelin-Chaab. "Novel Hybrid Cooling Concept for Battery Thermal Management Design". In: International Conference of Fluid Flow, Heat and Mass Transfer. June 2018. DOI: 10.11159/ffhmt18.149. URL: http://avestia.com/FFHMT2018_Proceedings/files/paper/FFHMT_149. pdf (visited on $06 / 09 / 2019$ ).

[63] Corey D White and K Max Zhang. "Using vehicle-to-grid technology for frequency regulation and peak-load reduction". In: Journal of Power Sources 196.8 (2011), pp. 3972-3980.

[64] C. Zhou, K. Qian, M. Allan, and W. Zhou. "Modeling of the Cost of EV Battery Wear Due to V2G Application in Power Systems". In: IEEE Transactions on Energy Conversion 26.4 (Dec. 2011), pp. 1041-1050. ISSN: 0885-8969. DOI: 10.1109/TEC. 2011.2159977. 


\section{Appendix A}

\section{OViN Data Distributions}

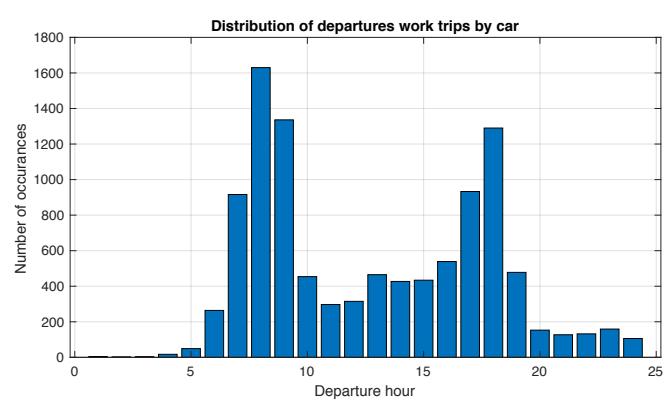

Figure A.1: Distributions of departures work trips by car

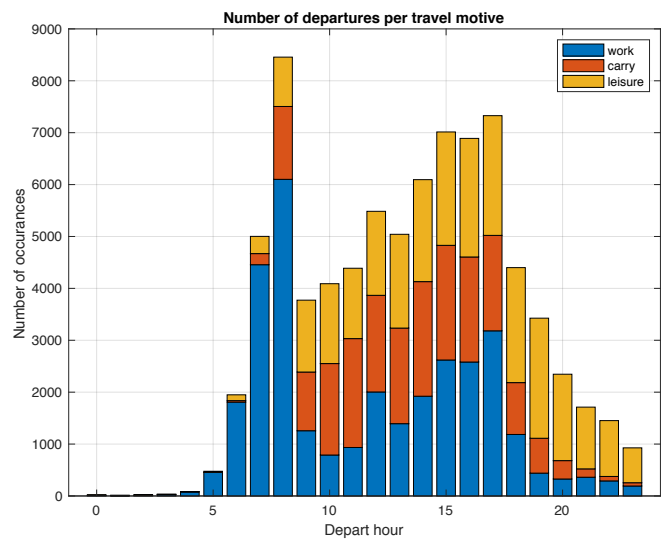

Figure A.3: Numbers of departure per travel motive

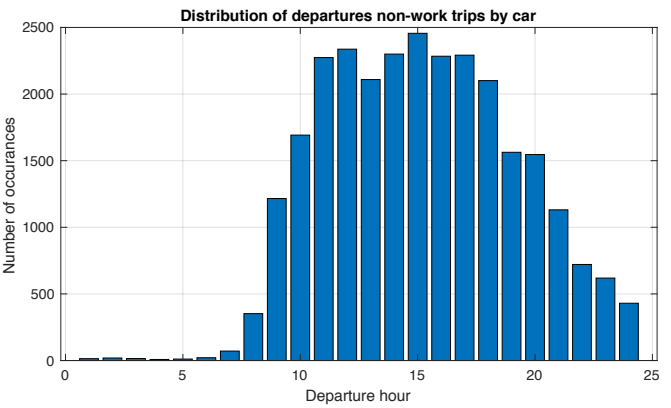

Figure A.2: Distributions of departures non-work trips by car

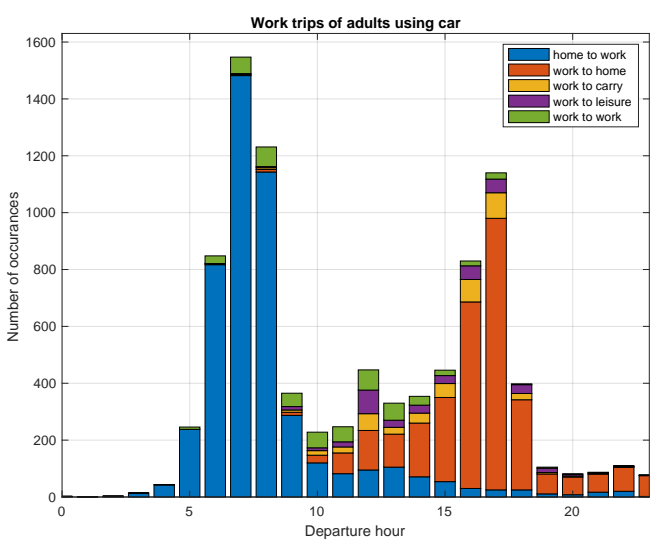

Figure A.4: Work trips of adults using car 


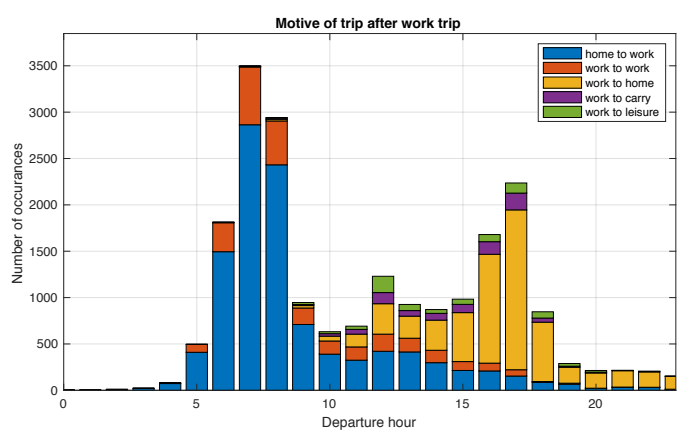

FIgURE A.5: Motive of trip after work trip

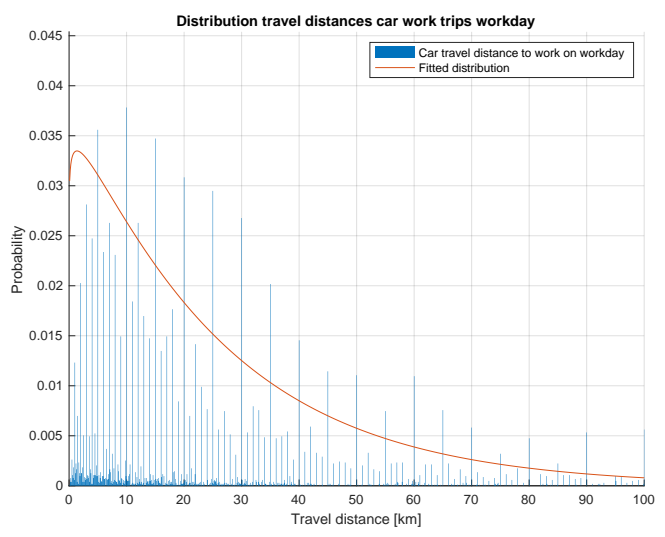

Figure A.6: Distribution travel distance car work trips workday

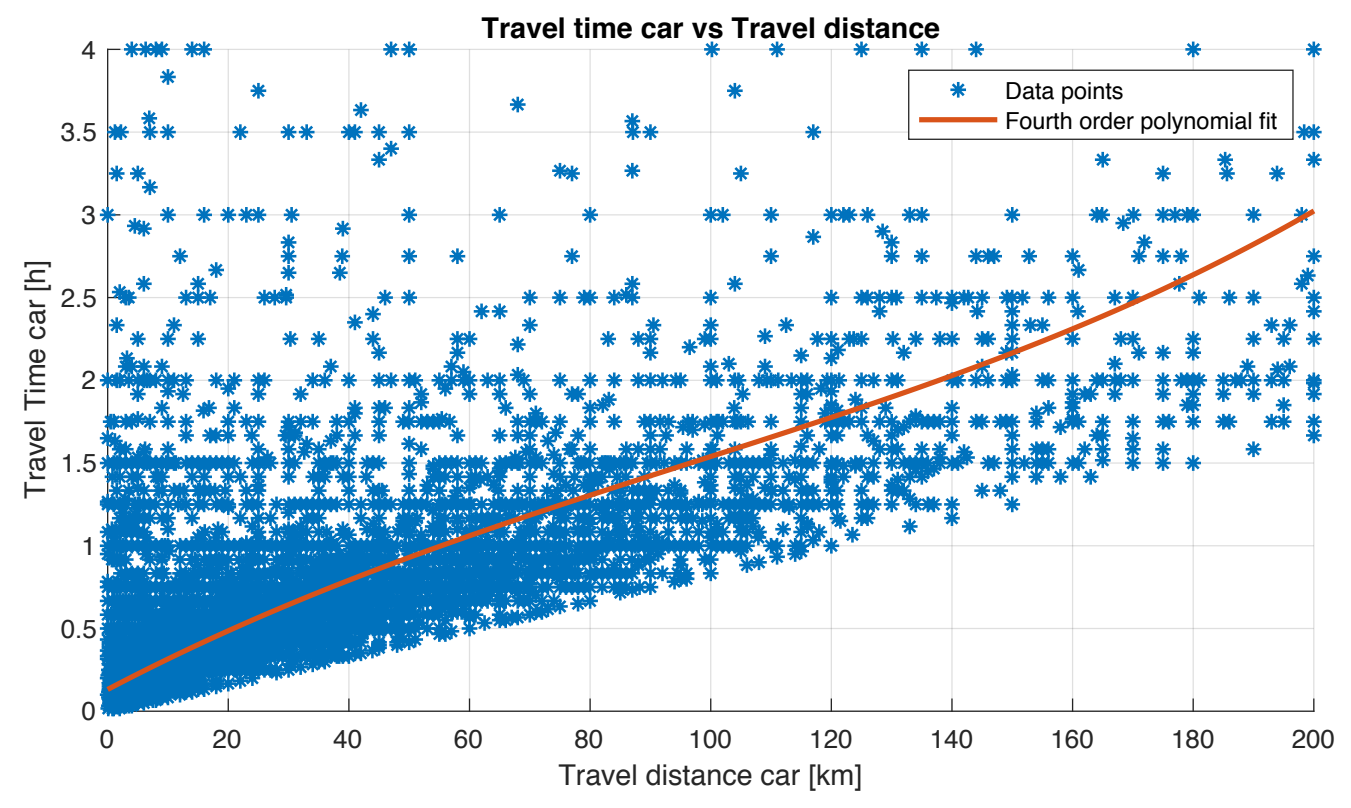

FiguRE A.7: Travel time car vs travel distance 


\section{Appendix B}

\section{Local Electricity Network Load}

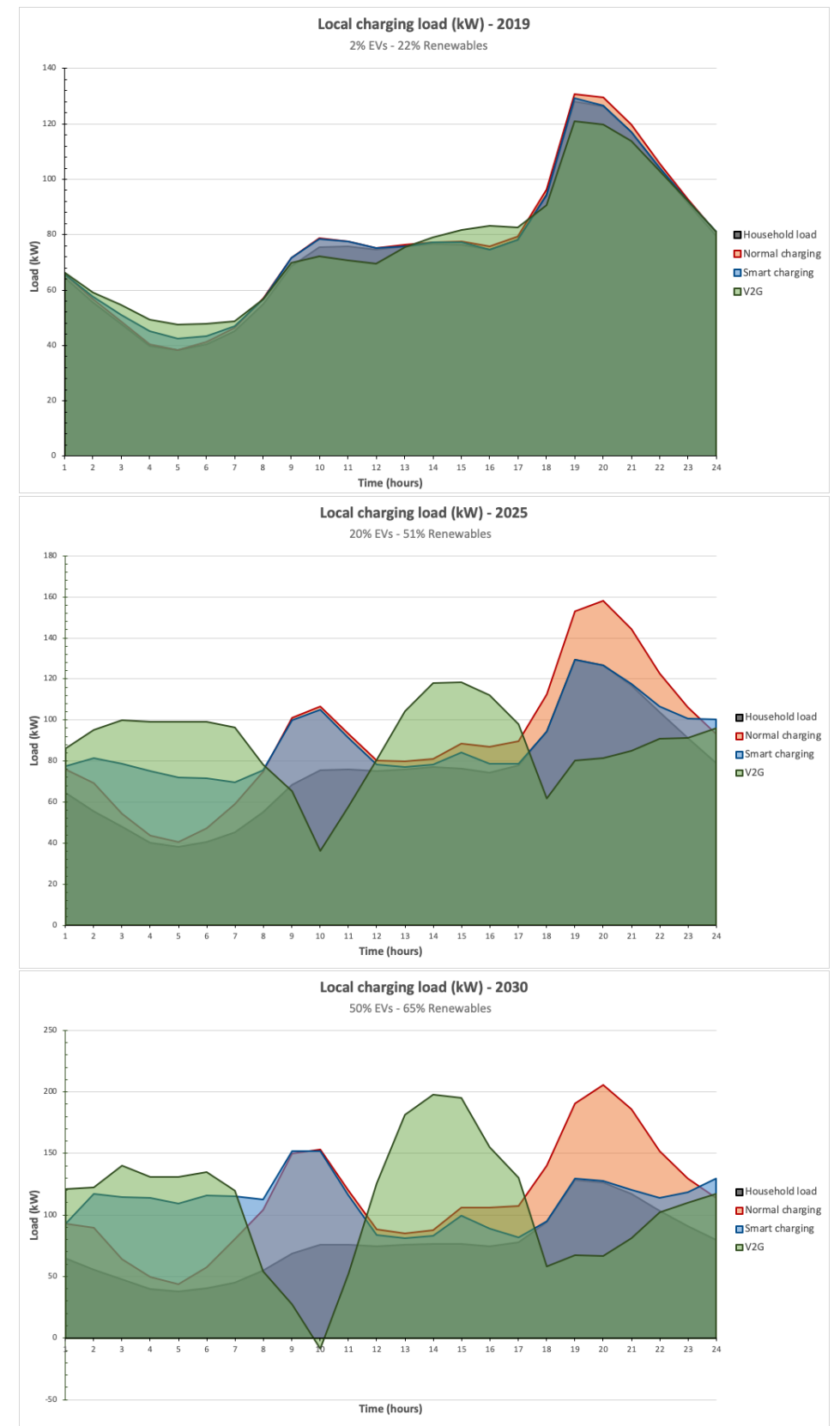

FigURE B.1: Local electricity load due to different charging strategies in 2019,2025 and 2030 


\section{Appendix C}

\section{Spot Market Prices Validation}

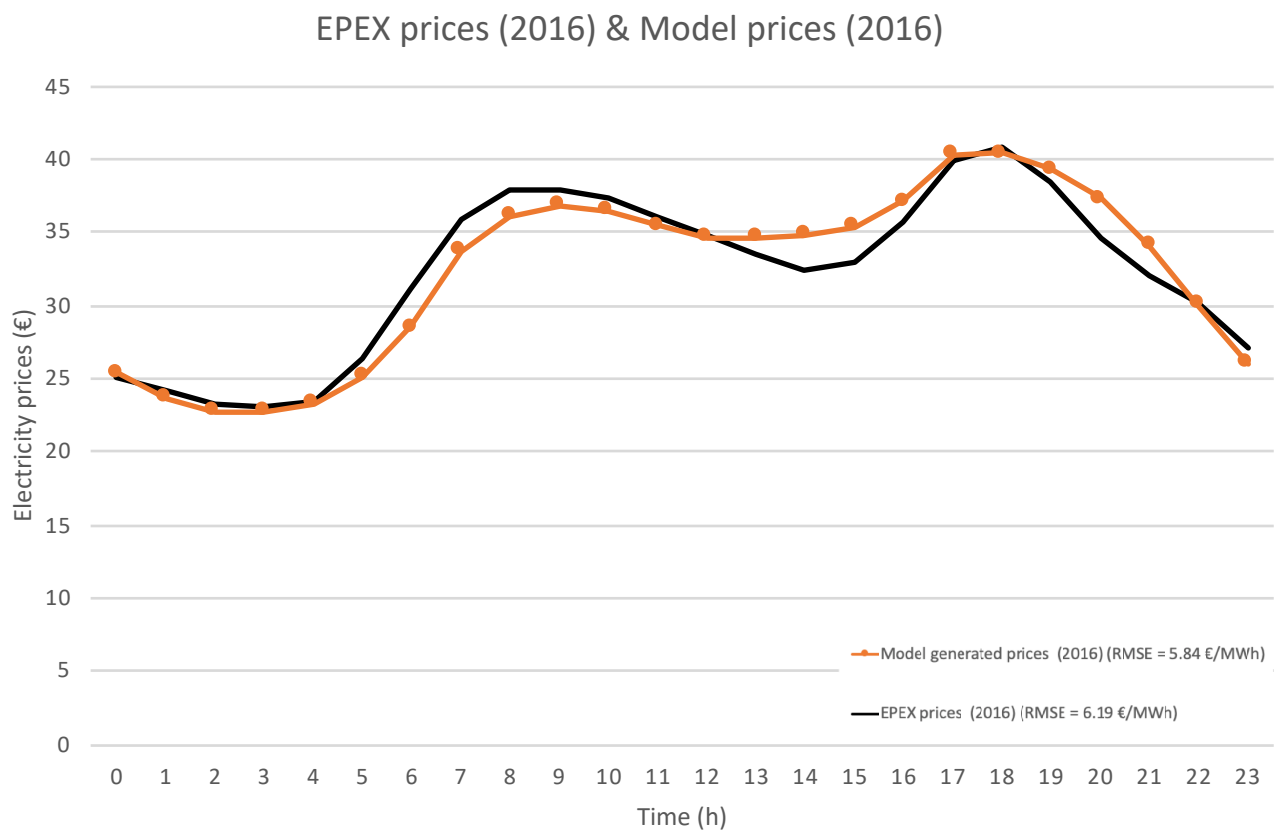

FIgURE C.1: Comparison of EPEX and Model generated average spot market price for 2016

\begin{tabular}{cccc}
\hline & UCS & CBCS & V2GS \\
\hline 2019 & 6.98 & 6.76 & 6.40 \\
2025 & 10.05 & 8.57 & 7.23 \\
2030 & 16.71 & 14.21 & 13.12 \\
\hline
\end{tabular}

TABLE C.1: RMSE values ( $€ / M W h)$ due to different charging strategies in 2019, 2025, 2030 